\title{
The underpinnings of the relationship of species richness with space and time
}

\author{
Samuel M. Scheiner,,${ }^{1,7}$ Alessandro Chiarucci, ${ }^{2}$ Gordon A. Fox, ${ }^{3}$ Matthew R. Helmus, ${ }^{4}$ Daniel J. McGlinn, ${ }^{5}$ \\ AND Michael R. Willig ${ }^{6}$ \\ ${ }^{1}$ Division of Environmental Biology, National Science Foundation, 4201 Wilson Blvd., Room 635, Arlington, Virginia 22230 USA \\ ${ }^{2}$ Biodiversity and Conservation Network, Department of Environmental Science "G. Sarfatti," University of Siena, 53100 Siena, Italy \\ ${ }^{3}$ Department of Integrative Biology, University of South Florida, Tampa, Florida 33620 USA \\ ${ }^{4}$ Key Laboratory of Tropical Forest Ecology, Xishuangbanna Tropical Botanical Garden, Chinese Academy of Sciences, \\ Kunming, Yunnan 650223 China \\ ${ }^{5}$ Department of Biology, University of North Carolina, Chapel Hill, North Carolina 27599 USA \\ ${ }^{6}$ Center for Environmental Sciences and Engineering and Department of Ecology and Evolutionary Biology, \\ University of Connecticut, Storrs, Connecticut 06269 USA
}

\begin{abstract}
Various ecological mechanisms influence the forms of species richness relationships (SRRs). These mechanisms can be gathered under five general categories: more individuals, environmental heterogeneity, dispersal limitations, biotic interactions, and multiple species pools. Often only the first two categories are discussed. In contrast, we examine all five and explore how they can influence the form of SRRs. We discuss how various sampling schemes and methods of SRR construction can be used to gain insight about how various processes influence species richness patterns. The field is ripe for probing these effects through more complex simulation models or more sophisticated mathematical approaches. To facilitate deeper understanding, we need to embrace the full spectrum of SRRs and reconsider the assumed common knowledge about the functional form of SRRs.

The relationship between species richness and the space or time over which it is sampled has received increasing attention over the past decade, resulting in extensive debates about terminology and methods of construction. These debates reflect deep conceptual issues; to resolve them we discuss the long history of species richness relationships (SRRs) and the connections among different methodological and terminological approaches. We reinforce recent calls to organize the variety of methods used to construct SRRs into a cohesive structure. SRRs are descriptors of various aspects of inventory $(\alpha-$ and $\gamma-)$ diversity and the various types of SRRs serve different purposes. Contrary to most claims, SRRs do not provide a direct measure of differentiation ( $\beta$-) diversity.
\end{abstract}

Key words: $\alpha$-diversity; area; $\beta$-diversity; biodiversity; differentiation diversity; $\gamma$-diversity; inventory diversity; species-area curve; species-area relationship; species richness.

\section{INTRODUCTION}

Species richness relationships (SRRs) represent the way in which the number of species varies as a function of the space or time over which it is sampled. A pattern of increasing richness with area has been called one of the few laws in ecology (Schoener 1976, Rosenzweig 1995, Lawton 2000, Lomolino 2000). Typically, SRRs

Manuscript received 17 July 2010; revised 16 November 2010; accepted 18 November 2010. Corresponding Editor: N. J. Gotelli.

${ }^{7}$ E-mail: sscheine@nsf.gov are graphical or mathematical models, most commonly of area alone (the species-area relationship, SAR; e.g., Preston 1962, Connor and McCoy 1979, Harte et al. $1999 a, b)$ and less commonly of time alone (e.g., White et al. 2006, Shurin 2007). The joint effects of time and area on species richness have been explored more recently (e.g., Adler et al. 2005, Fridley et al. 2006, White et al. 2006).

Estimates of species richness, whether for a community, region, biome or continent, are of fundamental importance to many issues in ecology and biogeography, such as in theoretical models of species coexistence (e.g., MacArthur and Wilson 1967, Hubbell 2001), as well as 
in applied problems of conservation, such as identifying biodiversity hotspots (e.g., Guilhaumon et al. 2008). We may want to evaluate the importance of historical contingency or resource limitation in determining the richness of fish in different estuaries. Or we may want to compare the richness of carnivores to that of herbivores in a particular region. Some important applied problems, such as evaluating the bacterial content of drinking water, may require estimates of richness as part of monitoring programs. For example, a recent study by Lyons et al. (2010) estimated a SRR for functional bacterial species on organic detritus, and suggested that such particles act like islands that can play an important role in the persistence and dispersal of pathogenic aquatic bacteria.

Thus, SRRs are useful in addressing many problems that can be gathered into two general categories. One use is estimation: SRRs are useful in estimating quantities related to $\alpha$-, $\beta$-, and $\gamma$-diversity (Whittaker 1960, Crist and Veech 2006, Tuomisto 2010a,b). Many studies use SRRs to make qualitative comparisons (which may or may not involve formal statistical tests) or as basic descriptors of different regions or taxa. The other use of SRRs is exploring ecological processes. Although SRRs themselves do not uniquely reflect underlying causal processes, they can play an important role in exploring those processes.

Estimating species richness requires some subtlety. First, species richness must be estimated as a density of species for a particular spatial or temporal grain (e.g., 23 species of herbaceous plants within a $100-\mathrm{m}^{2}$ plot, 10 moth species per hour of light-trap sampling) rather than as simply the number of species of an arbitrary unit (e.g., 82 species of nesting birds in a forest, area unstated). Second, the design and analysis of sampling schemes aimed at estimating richness can have important effects on the results. Some sampling designs are more efficient than others in a particular situation. Moreover, different designs address different questions. Because such questions often are formulated using similar terms (e.g., species richness, species-area curve), it is not always obvious that the questions are addressing different phenomena and quantities (e.g., richness within an area vs. differences in species composition among areas).

Empirical SRRs are caused by the responses of species to variation in abiotic, biotic, and geographic factors that affect survivorship, recruitment, dispersal, and speciation (Preston 1962, MacArthur and Wilson 1967, May 1975, Coleman et al. 1982, Hubbell 2001). SRRs are also affected by sampling design and measurement error (Hill et al. 1994, Gotelli and Colwell 2001, Scheiner 2003, Fridley et al. 2006). However, we ultimately observe SRRs because as sampling intensity increases, either by sampling a larger spatial area or sampling for a longer time period, more variation is encompassed with respect to underlying factors, thus increasing species richness. SRRs do not directly distinguish among mechanisms, as any particular relationship can be the result of different combinations of causes. However, a better understanding of how any particular mechanism might contribute to the form or parameterization of SRRs facilitates deductions about ecological process from patterns. Moreover, SRRs are inherently useful in themselves. For example, speciesarea curves are used to understand the number of species that can live on islands (e.g., Wardle et al. 1997, Lomolino 2000), to describe species diversity patterns during vegetation dynamics or following disturbance (e.g., Rejmánek and Rosén 1992, Chiarucci 1996, Inouye 1998), or to estimate species extinctions due to habitat loss (e.g., Harcourt et al. 2001, Hubbell et al. 2008).

Although nearly all discussions of the relationship of richness and space are based on areas, for some habitats (e.g., aquatic, soil, aerial), spatially based relationships may consist of different volumes. SRRs with respect to volume may differ from those with respect to area, but we are aware of very few attempts to describe volumebased relationships: Paivinen et al. (2004) reported a positive relationship between the number of myrmecophylous beetle species and the volume of ant nests; Schmit (2005) found a positive relationship between the macrofungal species richness and the volume of individual woody logs; Anjos and Zuanon (2007) reported a positive relationship between the number of fish species and the water volume in stream segments. In general, aquatic studies have paid more attention to volume than have terrestrial studies. For simplicity in the rest of the paper, we will discuss space in terms of area.

Finally, SRRs have a long, rich, and sometimes contentious history concerning their general shapes (e.g., log-linear vs. polynomial, nonasymptotic vs. asymptotic), the terminology used to describe and classify them, and the methods used to assess them (e.g., Scheiner 2003, Tjørve 2003). These debates have intensified in recent years (Scheiner 2003, 2004, 2009, Gray et al. 2004a, $b$, Dengler 2009), necessitating this review.

We have four overarching goals in this paper: (1) to explore the different kinds of questions that can be addressed using SRRs, (2) to examine how sampling scheme and type of data analysis are related to questions that can be addressed reasonably, (3) to clarify issues of terminology and methodology, and (4) to synthesize fragmented concepts and applications into a cohesive structure. We accomplish these goals by first examining the history of SRRs and then disentangle a number of complex conceptual issues related to various descriptors of diversity. We then discuss the ecological mechanisms that influence the shapes of SRRs and the sampling schemes used to generate them. We conclude by summarizing the major issues that require additional resolution, especially with regard to the development of mechanistic models that connect SRRs to ecological processes. 


\section{History of a ConcePt AND its Controversies}

\section{The form of SRRs}

The first published accounts of the relationship between species richness and area date to the work of de Candolle (1855), Watson (1859, cited in Rosenzweig 1995), and Jaccard (1901, 1908). This relationship subsequently was formalized as the "species-area curve," first by Arrhenius (1921) and Gleason (1922), and later by Cain (1938). The earliest use of SRRs was to determine the smallest sampling area needed to obtain reasonably accurate estimates of species richness or composition in a community (Gleason 1922, BraunBlanquet 1932, Cain 1938).

Early debates (McGuinness 1984) concerned the best sampling scheme and the mathematical function to use for those estimates: the power function $\left(S=a x^{b}\right.$, where $S$ is species richness, $x$ is area, and $a$ and $b$ are fitted constants) proposed by Arrhenius (1921), or the logarithmic function (often called the exponential function, $S=a+b \log (x)$ ) of Gleason (1922). Based on Preston's (1962) derivation of a power function from a lognormal species abundance distribution, it is widely held that the power function is the best model (e.g., Sugihara 1981, Wissel and Maier 1992, Rosenzweig 1995; but see McGlinn and Palmer 2009). As a result, a power function is usually assumed in an uncritical fashion (e.g., Drakare et al. 2006). The first systematic attempt to question this assumption was Connor and McCoy (1979), who compared 100 data sets for correspondence to linear, power, and logarithmic functions. They found that the power function fit best about one-third of the time, as did a linear model. Since then, a handful of papers have compared the fit of power and logarithmic functions (Williams 1995, He and Legendre 1996, Keeley 2003, Keeley and Fotheringham 2003, Sagar et al. 2003, Ulrich and Buszko 2003, Fridley et al. 2005, Guilhaumon et al. 2008). Often the logarithmic function fit as well or better than the power function.

Over the past 10 years, a variety of other functional forms have been proposed for SRRs (Tjørve 2003, 2009), so that the list has grown to 27 alternatives; see Dengler (2009: Table 2) and Tjørve (2009: Appendix 1). The list includes some functions that are nonasymptotic, including the power and logarithmic functions, and others that reach a plateau. In a comprehensive comparison of asymptotic and nonasymptotic functions, Stiles and Scheiner (2007) found that the best-fitting functions differed among sites. Although Dengler (2009) found a similar result, he concluded that the power function was the best fit for all of the data sets (Scheiner 2009). It is ironic that many researchers consider the power function to be the only correct model, whereas others continue to develop new models. The recent development of software that compares the fit of SRRs to multiple models (Guilhaumon et al. 2010) may encourage researchers to consider a variety of alternative forms.

Temporal SRRs have received less attention than spatial SRRs and were originally mentioned in the context of species abundance distributions (Adler and Lauenroth 2003, White et al. 2006, Carey et al. 2007, Shurin 2007). Grinnell (1922) was one of the first to document that species richness increases with sampling duration. He described qualitatively a species abundance distribution for California birds based on census data and described how the proportion of singleton species continually increased with sampling time (i.e., a leftskewed distribution when abundances are log-transformed; McGill 2003). Later, Fisher et al. (1943) provided a temporal SRR for lepidopteran species based on the number of individuals collected in light traps through time, fitting the resulting abundance distribution to a log-series model. Preston (1960) was the first to postulate that temporal and spatial SRRs are similar in mathematical form, and Rosenzweig (1998) further united these two types of SRRs, arguing that similar underlying mechanisms create both patterns. Further work has supported and added nuance to the assertion that temporal and spatial SRRs are similar (e.g., Adler 2004, White et al. 2006, Soininen 2010).

Recent work has demonstrated that the spatial and temporal scales of sampling interact to affect the shape of SRRs: the time-by-area interaction (Adler et al. 2005, Fridley et al. 2006, Soininen 2010). Thus, independent considerations of spatial and temporal relationships within a single study are unwarranted. Adler et al. (2005) compared temporal and spatial SRRs for a wide range of taxa and found that all of the data sets displayed negative time-by-area interactions: the slopes of spatial SRRs decreased as the temporal length of the study increased. Although Adler et al. (2005) hypothesized that this may reflect the presence of several ecological mechanisms, McGlinn and Palmer (2009) demonstrated that negative time-by-area interactions are not necessarily signatures of ecological processes and that positive time-by-area interactions are theoretically possible. For example, high-diversity ecosystems, such as the tropics, that have steep spatial SRRs show a lower rate of rise of temporal SRRs than low-diversity systems (White et al. 2006, Shurin 2007, Shurin et al. 2007, Soininen 2010).

\section{Two general classes of SRRs and further controversy}

There are two general sampling approaches for constructing SRRs, and they lead to different methods of calculation (Scheiner 2003, Carey et al. 2007). The first type of sampling arises by obtaining aggregates of larger and larger areas or longer and longer periods of time, so that smaller units are entirely contained within larger units. For these SRRs, the individual data points are not mathematically independent (i.e., they are confounded and represent part-to-whole associations). Examples of such relationships include: a nested set of 
TABLE 1. Examples of the six types of species richness relationships (SRRs), including features and scale parameters.

\begin{tabular}{|c|c|c|c|c|c|}
\hline $\begin{array}{l}\text { Type and } \\
\text { sampling } \\
\text { scheme }\end{array}$ & Species density & $\begin{array}{l}\text { Construction } \\
\text { spatially } \\
\text { explicit? }\end{array}$ & Grain & Focus & Extent \\
\hline I) nested & $\begin{array}{l}\text { no. species in a contiguous } \\
\text { sample unit of specified } \\
\text { size }\end{array}$ & yes & $\begin{array}{l}\text { sample unit nested } \\
\text { within the larger } \\
\text { or longer one }\end{array}$ & same as the grain & $\begin{array}{l}\text { the largest or } \\
\text { longest } \\
\text { sampling unit }\end{array}$ \\
\hline IIA) contiguous & $\begin{array}{l}\text { no. species in a contiguous } \\
\text { sample unit of specified } \\
\text { size }\end{array}$ & yes & $\begin{array}{l}\text { one or more } \\
\text { adjacent sampling } \\
\text { units }\end{array}$ & $\begin{array}{l}\text { cumulative area or } \\
\text { time of all } \\
\text { sampling units }\end{array}$ & $\begin{array}{l}\text { same as the } \\
\text { focus }\end{array}$ \\
\hline IIB) contiguous & $\begin{array}{l}\text { no. species in an } \\
\text { aggregated sample unit } \\
\text { of specified size }\end{array}$ & no & $\begin{array}{l}\text { one or more } \\
\text { aggregated } \\
\text { sampling units }\end{array}$ & $\begin{array}{l}\text { cumulative area or } \\
\text { time of all } \\
\text { sampling units }\end{array}$ & $\begin{array}{l}\text { same as the } \\
\text { focus }\end{array}$ \\
\hline $\begin{array}{l}\text { IIIA) noncon- } \\
\text { tiguous }\end{array}$ & $\begin{array}{l}\text { no. species in an } \\
\text { aggregated sample unit } \\
\text { of specified size }\end{array}$ & yes & $\begin{array}{l}\text { one or more } \\
\text { neighboring } \\
\text { sampling units }\end{array}$ & $\begin{array}{l}\text { cumulative area or } \\
\text { time of all } \\
\text { sampling units }\end{array}$ & $\begin{array}{l}\text { maximum } \\
\text { distance or } \\
\text { time among } \\
\text { sampling units }\end{array}$ \\
\hline $\begin{array}{l}\text { IIIB) noncon- } \\
\text { tiguous }\end{array}$ & $\begin{array}{l}\text { no. species in an } \\
\text { aggregated sample unit } \\
\text { of specified size }\end{array}$ & no & $\begin{array}{l}\text { one or more } \\
\text { aggregated } \\
\text { sampling units }\end{array}$ & $\begin{array}{l}\text { cumulative area or } \\
\text { time of all } \\
\text { sampling units }\end{array}$ & $\begin{array}{l}\text { maximum } \\
\text { distance or } \\
\text { time among } \\
\text { sampling units }\end{array}$ \\
\hline $\begin{array}{l}\text { IV) independent } \\
\text { units }\end{array}$ & $\begin{array}{l}\text { estimated no. species in } \\
\text { sample of a specified } \\
\text { size }\end{array}$ & no & $\begin{array}{l}\text { independent space } \\
\text { or time units }\end{array}$ & $\begin{array}{l}\text { cumulative area or } \\
\text { time of all } \\
\text { sampling units }\end{array}$ & $\begin{array}{l}\text { maximum } \\
\text { distance or } \\
\text { time among } \\
\text { sampling units }\end{array}$ \\
\hline
\end{tabular}

Note: See Table 2 for definitions of the scale components.

plots for plant species richness, or insect light traps with the SRR graphed as the total number of species captured after one day, two days, and so forth.

The second class consists of independent units, which typically differ in size or duration and generally are not contiguous. A typical SRR of this type consists of samples from a series of islands or lakes, although it is possible to design a study with replicated units of a given size (e.g., Lyons and Willig 1999, 2002, Bierregaard et al. 2001, Lindenmayer 2008). The units could also consist of geopolitical entities such as counties or states. For a time-based study, the data could consist, for example, of the number of plant species that colonized old fields that differ in age since abandonment, if one is willing to treat such samples as representing a single time series.

For convenience we refer to these two classes as aggregate and independent SRRs, respectively. We make this distinction for several reasons. The two classes differ in their possible mathematical forms. An aggregate SRR must be at least monotonically nondecreasing (i.e., reaching a plateau), or monotonically increasing, because smaller units are always contained within larger units. In contrast, because for an independent SRR the smaller units are not contained within the larger one, there is no necessity that a given larger unit has more species than smaller ones. Because of this difference in form, constraint, and the nature of the units (i.e., nested or not), the two classes differ to some extent in the mechanisms responsible for their shapes. Finally, aggregate and independent SRRs differ in the statistical methods that must be used in estimation because of the nonindependence of the former.

These different forms of construction are tied to a debate during the past few years over the terminology used for SRRs and what should be termed a SRR (Scheiner 2003, 2004, 2009, Gray et al. 2004a, b, Dengler 2009). Scheiner (2003) proposed a typology comprising six area-based relationships that arise because of differences in the scheme for collecting and aggregating sampling units (Table 1, Fig. 1). Type I consists of
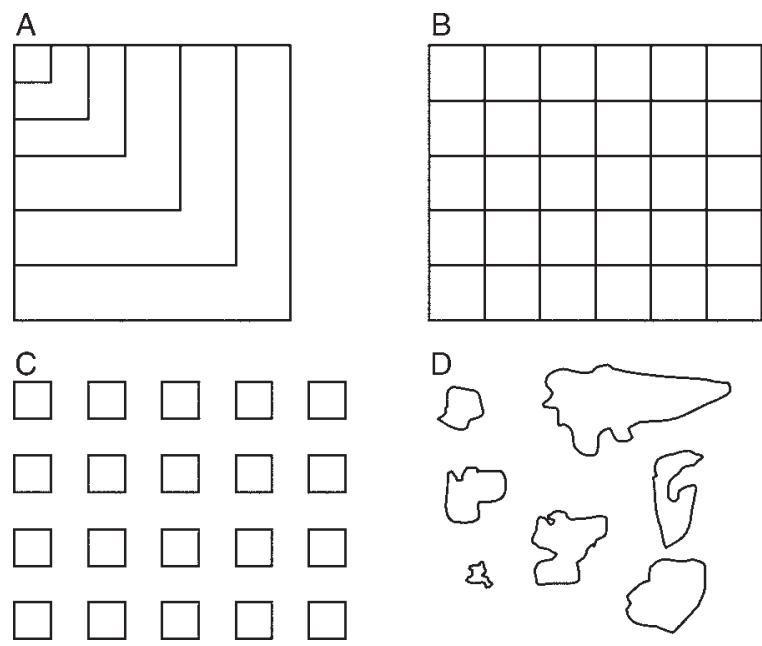

FIG. 1. Richness-area relationships can be built from four general sampling schemes: (A) strictly nested quadrats (Type I curves), (B) quadrats arrayed in a contiguous grid (Type II curves), (C) quadrats arrayed in a regular but noncontiguous grid (Type III curves), or (D) areas of varying size, often islands (Type IV curves). The specific schemes shown here are merely emblematic, not prescriptive. The nesting of quadrats in panel (A) could be from the center outward. The grid elements in panels (B) and (C) need not be square, regular in shape, or the same sizes, and those in panel (C) need not be regularly spaced. The areas in panel (D) could be contiguous (e.g., geopolitical units). This figure is from Scheiner (2003). 
TABLE 2. Measures of $\alpha-, \beta$-, and $\gamma$-diversity from the vegetation of the Oosting Natural Area of the Duke Forest, North Carolina, USA.

\begin{tabular}{|c|c|c|c|c|c|c|c|c|}
\hline \multirow[b]{2}{*}{ Grain $\left(\mathrm{m}^{2}\right)$} & \multirow[b]{2}{*}{ Focus $\left(\mathrm{m}^{2}\right)$} & \multicolumn{3}{|c|}{ Diversity } & \multicolumn{2}{|c|}{ Estimated species richness } & \multicolumn{2}{|c|}{ Functional form of SRR } \\
\hline & & $\alpha$ & $\gamma$ & $\beta$ & Spatial & Nonspatial & Spatial & Nonspatial \\
\hline 0.015625 & 4 & 0.8 & 54 & 64.0 & 78.1 & 74.1 & Weibull & Weibull \\
\hline 0.0625 & 16 & 2.1 & 79 & 37.8 & 239.4 & 147.8 & Lomolino & Lomolino \\
\hline 0.25 & 64 & 4.8 & 109 & 22.6 & 340.2 & 186.8 & Lomolino & Lomolino \\
\hline 1 & 256 & 9.6 & 138 & 14.3 & 626.7 & 257.5 & Lomolino & Lomolino \\
\hline 4 & 1024 & 17.9 & 174 & 9.7 & 643.3 & 294.7 & Weibull & Lomolino \\
\hline 16 & 4096 & 29.4 & 206 & 7.0 & 481.4 & 287.0 & Power & Lomolino \\
\hline
\end{tabular}

Notes: At each grain size, $\alpha$-diversity is the mean number of species in the 256 quadrats, $\gamma$-diversity is the total number of species in those quadrats, and $\beta$-diversity is $\gamma / \alpha$. For each grain size, Type IIIA (spatially explicit) and Type IIIB (nonspatially explicit) SRRs (species richness relationships) were constructed and used to estimate the total number of species in the entire $65536-\mathrm{m}^{2}$ area. The total number of species observed was 224 .

nested plots, one at each particular size. Type II consists of contiguous plots, with the curve built from averaging multiple combinations of areas of a particular size. Type III consists of noncontiguous plots, again building the curve from multiple combinations. Type IV consists of independent "islands" (that could be natural, such as oceanic islands, or artificial, such as plots) of different sizes. Types II and III are further subdivided into A and $\mathrm{B}$ versions depending on whether the multiple combinations are built using the spatial arrangement of the plots (e.g., nearest neighbors), or are built from all possible combinations of plots. Types I, II, and III are examples of aggregate SRRs; Type IV is equivalent to independent SRRs. Carey et al. (2007) extended this typology to time-based relationships. We note that even the "independent" units of a Type IV curve may not be causally independent (e.g., there may be spatial dependence due to migration among units: metacommunity dynamics), which would need to be considered when making inferences about causes.

Dengler (2009) separated area-based relationships into two classes: species-area relationships (SARs) and species-sampling relationships (SSRs). According to Dengler, SARs include all schemes in which species richness is calculated for contiguous units (Types I, IIA, and IV); all other schemes (e.g., Types IIB, IIIA, and IIIB) are SSRs. He made this distinction on the assumption that area only has ecological meaning if it is contiguous. We do not agree, for several reasons. First, many organisms use space discontinuously, just as many use time discontinuously. More generally, a sampling scheme used to describe some quantity is not equivalent to (and need not mirror) the quantity being studied. The problem for ecologists and biogeographers is how to estimate the relationship between richness and area or richness and time. In some cases, noncontiguous sampling is more efficient, for example through the use of stratified sampling among pre-identified habitat types when the overall domain is large. Finally, as we will see, the comparison of type A and B curves provides insight into ecologically important processes.

\section{Four components of scale}

Understanding the components of scale is central to resolving issues regarding SRRs, especially the factors responsible for their functional forms (Palmer and White 1994, Scheiner et al. 2000, Whittaker et al. 2001, Drakare et al. 2006, Dengler 2008). The four basic components are sampling unit, grain, focus, and extent (Table 2; see Scheiner et al. 2000, Dungan et al. 2002). The concepts of grain and extent are simple and widely accepted. The extent is the coarsest spatial or temporal scale of the samples, e.g., the area of the convex polygon that encloses all of the samples. The grain is the standardized unit to which all data are adjusted before analysis. The concept of sampling unit is rarely separated from that of grain because in most analyses the grain and sampling unit are identical. However, a common use of a SRR is to standardize data from different data sets to a common grain that will often be different from the grain of many of the original samples. Focus is also rarely acknowledged. Focus refers to the inference space (in the statistical sense) of the replicated units of analysis and typically equals the summed area or duration of the samples.

To understand these concepts, consider the following example: data comprising $1001 \times 1 \mathrm{~m}$ plots scattered across a 1-ha field. A SRR is constructed by computing the mean number of species at $1 \mathrm{~m}^{2}$ (all single plots), at 2 $\mathrm{m}^{2}$ (all pairs of plots), and so forth. In this study, the sampling unit is the $1 \times 1 \mathrm{~m}$ plot, the grain is $1 \mathrm{~m}^{2}$, the extent is $1 \mathrm{ha}$, and the focus of the SRR is $100 \mathrm{~m}^{2}$ because the relationship is based on the entire set of plots. In general, for a particular SRR, the grain is the size of the smallest unit used in its construction, the focus is the size of the total aggregation, and the extent is the total area from which the samples were drawn. The focus can be smaller than or equal to the extent, depending on the type and use of the SRR (Table 1).

For example, one might want to compare the number of species per $10 \mathrm{~m}^{2}$ with that of other sites. In this instance, the grain of this estimate is $10 \mathrm{~m}^{2}$, with the focus remaining $100 \mathrm{~m}^{2}$. This estimate is provided directly by the SRR. On the other hand, a comparison of 
TABLE 3. Glossary of terms associated with species richness relationships.

\begin{tabular}{|c|c|}
\hline Term & Definition \\
\hline$\alpha$-diversity & mean species diversity measured at a specified grain within a focus \\
\hline$\beta$-diversity & the effective number of communities within a focus \\
\hline Collector's curve & a curve reporting the number of species as a function of the collector's effort \\
\hline Contiguous sampling & the placement of sampling units so that they are adjacent in space or time \\
\hline Differentiation diversity & $\begin{array}{l}\text { how species abundance and composition differ across samples in space or time, most } \\
\text { often referred to as } \beta \text {-diversity or turnover }\end{array}$ \\
\hline Effective number of communities & $\begin{array}{l}\text { the number of communities at a specified grain within a focus where each unit consists of } \\
\text { a set of unique species at the mean species diversity }\end{array}$ \\
\hline Extent & the coarsest spatial or temporal scale that encompasses all of the sampling units \\
\hline Focus & $\begin{array}{l}\text { the scale at which grains are aggregated or summed; the statistical inference space of the } \\
\text { basic units of analysis }\end{array}$ \\
\hline$\gamma$-diversity & total species diversity measured at a particular focus \\
\hline Grain & $\begin{array}{l}\text { the standardized unit to which all data are adjusted before analysis, often equal to the } \\
\text { area or duration of the sampling unit }\end{array}$ \\
\hline Inventory diversity & the biological diversity in a specified unit, most often referred to as $\alpha$ - or $\gamma$-diversity \\
\hline Passive sampling & see random placement \\
\hline Proportional diversity & $\begin{array}{l}\text { the difference in, or ratio of, species richness measured at different grains, most often } \\
\text { referred to as } \beta \text {-diversity }\end{array}$ \\
\hline Random placement & $\begin{array}{l}\text { the process by which species richness is determined by the number of individuals in a } \\
\text { sample due to the movement of individuals among patches or communities }\end{array}$ \\
\hline Rarefaction & $\begin{array}{l}\text { the process of standardizing the species richness of collections of different size to a } \\
\text { common number of individuals or samples }\end{array}$ \\
\hline Rarefaction curve & any species richness relationship that is used for the process of rarefaction \\
\hline Sampling unit & the spatial and/or temporal dimensions of the collection unit \\
\hline Species accumulation curve & $\begin{array}{l}\text { a curve showing the number of species accumulated in relation to the number of units } \\
\text { sampled }\end{array}$ \\
\hline Species-area curve & $\begin{array}{l}\text { a graphical or mathematical representation of the relationship between species richness } \\
\text { and area sampled }\end{array}$ \\
\hline Species density & species richness per unit area, volume, or duration \\
\hline Species richness & the number of species \\
\hline Species richness relationship & $\begin{array}{l}\text { any relationship that describes how species richness changes as a function of the area } \\
\text { and/or time over which those species are sampled }\end{array}$ \\
\hline Strictly nested sampling & the placement of sampling units so that each one is entirely contained within a larger one \\
\hline
\end{tabular}

Note: Although several of these terms have been used in multiple ways in the literature, our definitions refer to the most common usages and to our usage in this paper.

richness per ha would require extrapolation from the SRR, so that the grain and focus equal $1 \mathrm{ha}$. The shift in focus occurs because the plots are assumed to be a representative sample of the entire field. An extrapolation beyond 1 ha, e.g., a comparison of richness per 10 ha, would make the grain of the estimated richness greater than the extent, but requires an assumption that the sampled extent is representative of the extrapolated area. Thus, SRRs can facilitate comparisons among different data sets with different-sized sampling units and at multiple grain sizes. See Scheiner et al. (2000) for a discussion of how changing grain, focus, and extent can alter the perceived relationship between species richness and other factors.

To make these concepts more concrete, we illustrate them with data from a vegetation survey of the Oosting Natural Area of the Duke Forest, North Carolina, USA (Reed et al. 1993, Palmer and White 1994, Palmer et al. 2007, Chiarucci et al. 2009) (see Plate 1). The vegetation was sampled in a $16 \times 16$ grid of 256 contiguous modules, each module being $16 \times 16 \mathrm{~m}$. Six nested quadrats (with sides of $0.125,0.25,0.50,1,2$, and $4 \mathrm{~m}$ ) were located in the southwestern corner of each module, and in each the presence of all vascular plant species was recorded (Reed et al. 1993). For these data, the grain size is the area of a single quadrat, the focus is the sum of the areas of the 256 quadrats, and the extent is the size of the entire sampled grid (65 $536 \mathrm{~m}^{2}$; Table 2). For each grain size, we constructed Type IIIA (spatially explicit) and Type IIIB (nonspatially explicit) SRRs; see Chiarucci et al. (2009) for methods details. Functions were fit to the SRRs using mmSAR (Guilhaumon et al. 2010) and the best-fit function was chosen based on AIC values.

\section{Terminology}

We recognize that calls for terminology reform can often be a case of tilting at windmills. However, the nonstandardized lexicon associated with SRRs often leads to unnecessary confusion (Table 3). Thus, we sort through this terminology and advocate a more precise usage. We chose the term "species richness relationships" because this phrase does not come with conceptual baggage and it clearly focuses on the response variable in the relationship: species richness.

Other terms focus on the independent variable, e.g., species-area curve. As such, they are appropriate if used in a simple, consistent fashion. Thus "species-area curve" or our preferred "species-area relationship" should only be used when the relationship is derived 
from area-based samples. We use the term "relationship" rather than "curve" to emphasize the generality of the functional form. These can be further specified depending on the sampling and accumulation protocol, e.g., a Type IIA richness-area relationship.

Sometimes SRRs are referred to as species accumulation curves (Gotelli and Colwell 2001, Carey et al. 2007, Shurin 2007). However, that phrase fails to specify either the independent or response variable. Often one has to further specify whether it is an individual-based or a sample-based species accumulation curve (e.g., Gotelli and Colwell 2001). Gray et al. (2004a) state that because species accumulation curves measure different properties than species-area curves, they should not be lumped into the same category. We contend that species accumulation curves are simply one type of SRR and, as such, provide one of multiple insights about ecological patterns and processes.

"Collector's curve" is a traditional usage that can be similarly ambiguous because the name contains no information about either the sampling method or the response variable. Although the term "collector's curve" could be used to indicate a general process of accumulating something, it needs further clarification.

The term "rarefaction curve" can be similarly problematic because rarefaction is a procedure that can be done using various types of SRRs, as well as other methods. This term originally referred to a specific mechanisms for "rarefying" collections of different size to a common number of individuals (Sanders 1968). Later the use was expanded to the rarefaction of a common number of samples (Shinozaki 1963, Kobayashi 1974, Smith et al. 1985). Sample-based rarefaction methods correspond to Type IIB and IIIB SRRs. The exact formula for calculating the expected number of species in a given number of sampling units was discovered independently several times over a period of 40 years (Chiarucci et al. 2008), with the first authors focusing on species-area curves (Kobayashi 1974, Holthe 1975, Engen 1976, Smith et al. 1985).

\section{SRRs AS DESCRIPTORS OF BIODIVERSITY}

The study of biodiversity has long been hampered by ambiguous concepts and confusing terminology (Table 3). Whittaker's (1960) work laid the foundation for decades of research on the spatial decomposition of diversity, but was also the source of some difficulty because he used terms like $\beta$-diversity (and even $\alpha$ diversity) to mean more than one thing. As a result, these terms have many different definitions in the literature, and $\beta$-diversity has been seen by some as a key idea and by others as an abstruse concept (Jurasinski et al. 2009, Tuomisto 2010a).

Whittaker (1960) originally defined $\alpha$-diversity as the mean of diversities measured at the scale of local communities, and $\gamma$-diversity as the total diversity of communities in a landscape. However, later and somewhat confusingly, Whittaker (1972) used the term $\alpha$-diversity to refer to any particular local measurement of diversity, not necessarily the mean of local diversities. In that paper, he also defined $\delta$-diversity as the total diversity of a region. However, the exact meanings of local, landscape, and region were not precisely defined, leading numerous authors to use these terms to refer to measures at different grains. Because $\alpha-, \gamma-$, and $\delta$ diversity are in the same units, both Scheiner (1992) and Jurasinski et al. (2009) suggested that these terms are best subsumed under the label inventory diversity, a term initially suggested by Whittaker (1972).

Recent work by Tuomisto $(2010 a, b)$ has resolved many conceptual and terminological issues, and her work establishes the framework for our treatment. Key to this framework is the understanding that the quantities of $\alpha-, \beta$-, and $\gamma$-diversity are not tied to a fixed grain, focus, or extent, but rather are defined by the way they are estimated in each particular study. The total species diversity measured at a particular focus is $\gamma$ diversity. In contrast, $\alpha$-diversity is the estimated species diversity at a particular grain within that focus. In the previous example, $\gamma$-diversity is the total number of species in the cumulative $1001-\mathrm{m}^{2}$ plots, and $\alpha$-diversity is the mean number of species $/ \mathrm{m}^{2}$, based on all 100 plots. If instead we were to consider just a particular $1-\mathrm{m}^{2}$ plot, then the number of species in that plot would be its $\gamma$ diversity. One virtue of Tuomisto's $(2010 a, b)$ definitions is that they make it possible to mathematically define $\alpha$-, $\beta$-, and $\gamma$-diversity and the relationships among them. Despite the importance of these quantities, their previous, multiple definitions made these relationships unclear. In essence, Tuomisto has returned us to Whittaker's original 1960 definitions, but now shorn of any particular scale. For measures of diversity beyond richness, $\alpha$ - and $\gamma$-diversity can also be estimated by weighting each species by, for example, abundance, frequency, biomass, trait differences (e.g., Petchey and Gaston 2002), or phylogenetic relatedness (e.g., Helmus et al. 2007). Such weightings provide a measure of effective diversity.

$\beta$-diversity is the estimated effective number of sampling units (e.g., communities) in the study (Hill 1973, Jost 2006, Baselga 2010, Tuomisto 2010a), where the effective number is the number of sampling units necessary to contain the total $(\gamma-)$ diversity, given that each unit consists of a set of unique species each with a mean diversity equal to $\alpha$; for species richness, $\beta=\gamma / \alpha$. Note that the units of $\beta$-diversity (numbers of communities) differ from the units of $\alpha$ - and $\gamma$-diversity. (This formula is for species richness data; see Tuomisto [2010a], which provides a more thorough treatment with a formula that accounts for abundance, and shows the relationship of this measure of $\beta$-diversity to other measures, including those associated with additive partitioning $(\gamma-\alpha)$.) Some may find it useful to notice a crude parallel between these effective quantities $(\alpha$ - and $\beta$-diversity) and the notion of effective population size from population genetics. 


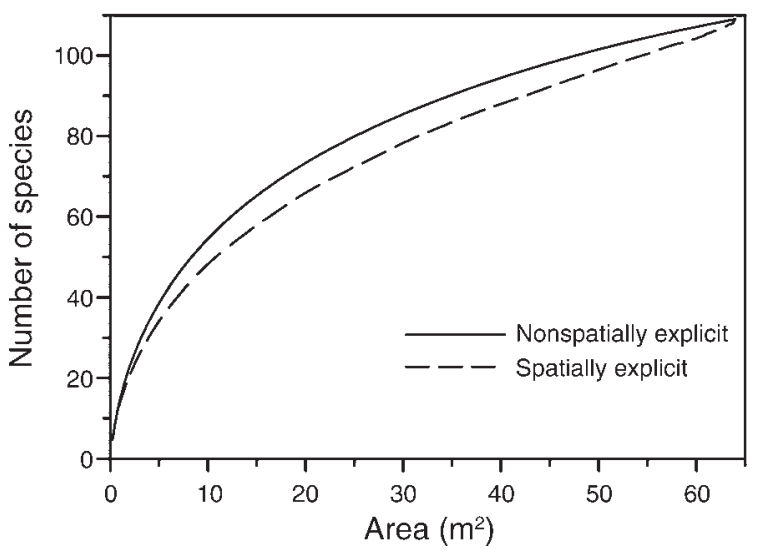

FIG. 2. Type IIIA (spatially explicit) and Type IIIB (nonspatially explicit) SRRs (species richness relationships) for the $0.25-\mathrm{m}^{2}$ quadrats of the Oosting Natural Area of the Duke Forest, North Carolina (USA) vegetation survey. The points along the spatially explicit curve are measures of mean $\alpha$ diversity; those of the nonspatially explicit curve are measures of mean $\gamma$-diversity. See Chiarucci et al. (2009) for additional details on the construction of these curves.

\section{Inventory: $\alpha$ - and $\gamma$-diversity}

By definition, SRRs measure species richness and its pattern of change across spatial or temporal scales. Different designs can be used to estimate different components of inventory diversity ( $\alpha$ - and $\gamma$-diversity) at different grains, such as when sampling plant diversity at multiple spatial scales within standardized sampling plots (e.g., Shmida 1984, Stohlgren et al. 1995, Peet et al. 1998, Chiarucci et al. 2001).

Spatially explicit curves (Types IIA and IIIA; Fig. 2, Table 1) estimate mean $\alpha$-diversity and its rate of change with sampling scale; put differently, the slope of a Type A curve is an estimate of the rate of change of mean $\alpha$-diversity as grain increases (Tuomisto 2010b). Alternatively, nonspatially explicit curves (Types IIB and IIIB) estimate mean $\gamma$-diversity and its rate of change as the focus increases. The conceptual difference between $\alpha$ - and $\gamma$-diversity is thus tied to the relationship between the area of the grain and the focus. If the grain is less than the focus, average species richness is an estimate of $\alpha$-diversity; if the grain equals the focus, average richness is an estimate of $\gamma$-diversity.

This conceptual difference also relates to Type A and Type $\mathrm{B}$ relationships based on the different ways in which those SRRs are constructed. The units used to construct the spatially explicit SRRs are always nearest neighbors, whereas those for the nonspatially explicit SRRs are averaged over all possible sets of plots that can yield virtual sampling units of a particular size. (Although we use the terms "spatial" and "nonspatial" for these estimation procedures, the same approaches could equally well be used for temporal samples.) Any data set adequate for estimating a spatially explicit curve is also adequate for estimating a nonspatially explicit curve. Because they provide different kinds of informa- tion, estimates of both kinds of SRR for a single data set can be informative. If the spatially explicit and nonspatially explicit relationships differ from one another (Fig. 2), this indicates intraspecific spatial aggregation of individuals (Chiarucci et al. 2009). We are aware of few cases in which both kinds of curve have been constructed from the same data (e.g., Collins and Simberloff 2009).

Type II and III curves constructed from the same number of equal-sized plots will differ in extent (Fig. 1). This difference leads to an important reason for using a Type III (noncontiguous) rather than Type II (contiguous) design when sampling from a large study area or time period, so as to make inferences about that larger area or time period. If environmental heterogeneity occurs on a relatively large spatial or temporal scale, for the same area or duration, noncontiguous plots are more efficient at capturing that heterogeneity. For example, we might sample identified habitat types in a proportional manner (i.e., a stratified random sample). As with any sampling design, the inferences depend on the design being biologically reasonable.

Because they consist of a single data point at each grain, data sets used to construct Type I SRRs (Fig. 1, Table 1) cannot be used to estimate $\alpha$-diversity. This type of SRR is estimated by fitting a model to the relationship between a single estimate of $\gamma$-diversity (not the mean of $\gamma$ ) and size of the sample unit. Thus the curve can be interpreted either as an estimate of how $\gamma$ diversity grows with the extent of the study area, or as a description of how $\gamma$-diversity in a sampling unit grows with the size of that sampling unit.

In independent (Type IV) SRRs, the points are individual units that represent independent draws from a regional species pool. If units are distant enough or isolated enough, the units are not necessarily drawn from the same species pool. Each point is an observed $\gamma$ diversity, but one cannot interpret the curve as describing how $\gamma$-diversity changes with sample unit size.

The transformation of the axes for the graphical representation of a SRR can influence its interpretation. If richness is expressed on a logarithmic scale, then the quantities estimated are not diversities, but entropies (in the sense that the Shannon-Weiner diversity index is a measure of informational entropy) and the interpretation of the slopes changes in an analogous fashion. Again, we urge the interested reader to see Tuomisto $(2010 b)$ for a detailed discussion.

Estimates of diversity can also differ depending on whether a SRR is given as an accumulation of individuals or as an accumulation of samples (Gotelli and Colwell 2001). This distinction is important when SRRs are used to make comparisons of $\gamma$-diversity among data sets that differ in individual densities, because the data set with the highest estimated $\gamma$ diversity can differ depending on whether sample-based or individual-based relationships are used (e.g., Cannon et al. 1998). 
With regard to estimates of inventory diversity, SRRs are used in a variety of ways. Although SRRs are often used to determine minimum sampling areas, which was the earliest use of species-area curves, many have questioned the practicality of such application (Barkman 1989, van der Maarel 1996, Chytrý and Otýpková 2003). A similar procedure can be used for determining sampling intensity for temporal data (Fisher et al. 1943), as has been done for organisms with a reduced detectability, such as fungi (Arnolds 1981, De Dominicis and Barluzzi 1983), or those with high mobility, such as butterflies (Soberón and Llorente 1993).

Further complications occur when the sampling units themselves are mobile, such as surveys of microbial diversity within hosts. First is the problem of what dimensions to assign to the sampling units. Simply counting hosts assumes that all hosts are equal; i.e., they are all the same ecological size. This assumption may be reasonable, but at a minimum needs to be explicit. Second is the problem of how to build the SRR. Mobile units are not contiguous, so they can only be used to construct Type III curves. A Type IIIB curve is straightforward to construct; in contrast, a Type IIIA curve would require information on contact or proximity frequency for determining nearest neighbors. Depending on the mode of transmission (direct, vector, environmental transport) and the movement patterns or behaviors of the hosts, the spatially closest may not be the most frequent transmission pairs. As far as we are aware, the theoretical and practical aspects of these issues have not been explored.

SRRs are commonly used to standardize estimates of inventory richness across different sites or times. Although seemingly straightforward, accurate comparisons need to account for differences in the spatial or temporal dispersion of the sampling units in each study (Condit et al. 1996, Chiarucci et al. 2009). Such standardization is a form of interpolation and, thus, an estimate of $\alpha$-diversity. Therefore, these estimates should be done using a spatially explicit SRR (i.e., Type IIA or IIIA).

The use of SRRs for extrapolation is complex, because one is trying to answer a question outside the domain of the data. Extrapolation can be done to grains both larger or smaller than the grain and focus of the data, and to just outside the extent of the data or far outside it. The latter type of extrapolation is frequently used when direct sampling is not possible, such as the species richness within a geopolitical unit, biome, or continent (e.g., Gitay et al. 1991, Colwell and Coddington 1994, Wilson and Chiarucci 2000). Because extrapolation estimates $\gamma$-diversity, it should be done using a nonspatially explicit SRR (e.g., Type IIB or IIIB).

For the Oosting Natural Area data, Type IIIA and IIIB curves differed in their extrapolation accuracy, with Type A curves always having a greater estimated species richness than Type B curves, even when the form of the function was the same (Table 2). For the smaller grain

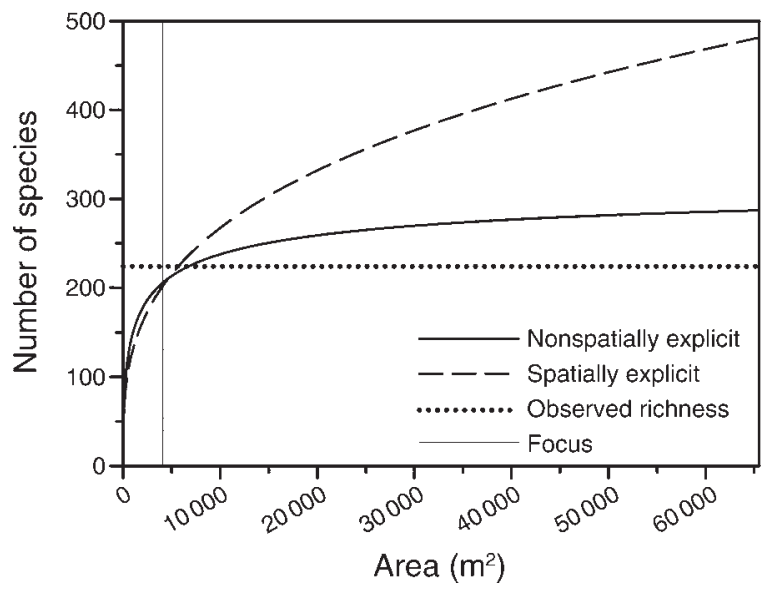

FIG. 3. Accuracy of extrapolated species richness estimates for Type IIIA (spatially explicit) and Type IIIB (nonspatially explicit) SRRs for the $16-\mathrm{m}^{2}$ quadrats of the Oosting Natural Area of the Duke Forest, North Carolina vegetation survey. The dotted horizontal line indicates the total observed species richness at $65536 \mathrm{~m}^{2}$, and the thin vertical line indicates the total area (focus) of the samples at $4096 \mathrm{~m}^{2}$.

sizes, the Type A and B curves did not differ in functional form, and at a grain size of $4 \mathrm{~m}^{2}$, both functions were asymptotic. The discrepancy in functional form was greatest at the largest grain size, $16 \mathrm{~m}^{2}$, where the estimated Type A (spatially explicit) SRR function was nonasymptotic (a power function) and the Type B SRR was asymptotic (a Lomolino function). Dengler and Oldeland (2010) assert that functional forms will differ between contiguous (Type II) and noncontiguous (Type III) SRRs; further exploration of the Oosting data could address that issue. Concentrating on just the Type B curves, grain and focus affected the accuracy of extrapolation: a small grain $\left(\leq 0.25 \mathrm{~m}^{2}\right)$ and focus $\left(\leq 64 \mathrm{~m}^{2}\right)$ underestimated the true species richness of the entire area, whereas a larger grain $\left(\geq 1 \mathrm{~m}^{2}\right)$ and focus $\left(\geq 256 \mathrm{~m}^{2}\right)$ overestimated the true species richness (Table 2, Fig. 3). In this simple analysis, we did not consider other functions with AIC values that were very similar to the best-fit function; model averaging (Guilhaumon et al. 2010) might provide better extrapolations. These issues, including the size of the grain and focus relative to the extent, await comprehensive exploration.

Finally, SRRs are used for conservation purposes when the intent is to design reserves of sufficient size to encompass all or most of the species in a region (e.g., Desmet and Cowling 2004), to investigate how fragmentation may reduce the number of species supported by a particular habitat (e.g., Hill and Curran 2001), or to predict species extinction under different scenarios of habitat loss (e.g., Hubbell et al. 2008).

\section{$\beta$-diversity}

Ecologists often use the term $\beta$-diversity informally, to refer to species turnover or changes in species 
composition from sample to sample. However, as Jurasinski et al. (2009) suggest, this notion is rather confusing, as reflected in the large number of conceptually different quantitative metrics of $\beta$-diversity. Those measures can be summarized into three broad categories: the ratio of regional and local diversities, the difference in regional and local diversities where that difference can be absolute or proportional, and differences in species composition among samples; see Gurevitch et al. (2006: Table 15.2) and Tuomisto (2010a: Table 2). The many different approaches to estimating $\beta$-diversity (Jurasinski et al. 2009) are partly a result of this multiplicity of verbal definitions. Metrics of $\beta$-diversity that can be stated in terms of the effective number of compositional units or communities (Tuomisto's true $\beta$-diversity) have the virtue of having a clear ecological meaning (Jost 2007, Tuomisto 2010a, b).

If there were no spatial patchiness or effects of random sampling, an unlikely combination of characteristics, Type II and III SRRs would be identical. In empirical data sets, however, they differ, and the differences reflect $\beta$-diversity. Importantly, the slopes of SRRs are not estimates of $\beta$-diversity, as erroneously asserted by numerous authors (e.g., Connor and McCoy 1979, Ricotta et al. 2002, Scheiner 2003, 2004, Passy and Blanchet 2007, Jurasinski et al. 2009). As explained previously, those slopes are in units of rates of change of expected $\alpha$ - or $\gamma$-diversity. If either of those slopes was an estimate of $\beta$-diversity, it would be possible to state the slope in terms of the effective number of compositional units or communities, which is not the case. As Tuomisto $(2010 b)$ points out, however, slopes of Types II and III SRRs can estimate components of $\beta$-diversity related to both absolute and proportional species turnover.

Estimates of $\beta$-diversity depend on the relative grain and focus used to measure $\alpha$ - and $\gamma$-diversity (Table 2). As the size of the unit used to measure $\alpha$-diversity increases for a particular focus, $\beta$-diversity approaches 1. Although $\alpha-, \beta$-, and $\gamma$-diversity can be measured with units of any size, this effect of the relative sizes of the grain and focus means that they are interdependent and ecological interpretations of $\beta$-diversity depend on this interdependence. This interdependence is especially important when attempting to make comparisons of $\beta$ diversity among data sets.

\section{Describing biodiversity}

SRRs calculated in different ways (e.g., Type II vs. III, A vs. B) will lead to different results, because they estimate fundamentally different quantities (Tuomisto $2010 a, b)$. Rather than worrying about which kind of estimate is the true SRR (Dengler 2009), the most useful approach is to use the variety of types to provide information on $\alpha$ - and $\gamma$-diversity as well as on the ways in which they change over space and time. If data are adequate for a Type II curve, then they are adequate for a Type III curve (although the opposite is not necessarily true), so there is little reason not to examine both kinds of pattern. That said, little is known about the statistical efficiency of the estimates derived from any of these SRRs. Different sample sizes or sampling intensities may be needed for satisfactory estimates of spatially explicit (Types IIA and IIIA) vs. nonspatially explicit (Types IIB and IIIB) SRRs. Indeed, now that Tuomisto $(2010 a, b)$ has clarified the conceptual basis for the different components of biodiversity, substantial progress can be made in studying the purely statistical aspects of such estimates (e.g., Colwell et al. 2004, Shen and $\mathrm{He} 2008$ ).

As previously discussed, $\beta$-diversity cannot be estimated from SRRs, but some components of $\beta$-diversity can (Tuomisto 2010b). One can use a nonspatially explicit SRR to estimate effective species turnover. The difference between the estimated $\gamma(n)$ (total species richness for the entire set of samples) and $\gamma(1)=\alpha$ (mean species richness for single samples) gives the mean of the absolute effective turnover for samples of $n$ units; this estimate can be scaled to give Whittaker's (1972) effective turnover for the entire data set $[(\gamma-\alpha) / \alpha]$. Similarly, the estimates of $\alpha$-diversity in a spatially explicit SRR can be used to estimate turnover as sampling units increase in size, and can be scaled to estimate the proportional effective turnover for the entire data set at any particular grain accommodated by the data $[(\gamma-\alpha) / \gamma]$. As with the SRRs themselves, there is a need for research on the statistical properties of these estimates.

\section{CAuses of SRRs}

Many mechanisms underlie the shape of any particular SRR. These mechanisms can be grouped into five general classes: (1) more individuals, (2) environmental heterogeneity, (3) dispersal limitations, (4) biotic interactions, and (5) multiple species pools. Often, only the first two classes are discussed, although all five have been mentioned in one context or another.

\section{More individuals}

By including more sampling units (a larger area or a longer time), more individuals are invariably sampled. Independent of the other classes of processes that we will discuss, sampling more individuals typically increases species richness and thus provides a purely statistical expectation for SRRs (McGuinness 1984). This process has been referred to variously as passive sampling (Connor and McCoy 1979), random placement (Turner and Tjørve 2005), the rarefaction effect (Palmer et al. 2008), and the sampling effect (McGlinn and Palmer 2009). We prefer "more individuals" because the name describes the process.

The more-individuals effect has typically been approached by comparing the observed SRR with an expected SRR that is derived using a permutation procedure or an analytical model (e.g., Arrhenius 1921, Coleman 1981, Adler et al. 2005, McGlinn and Palmer 


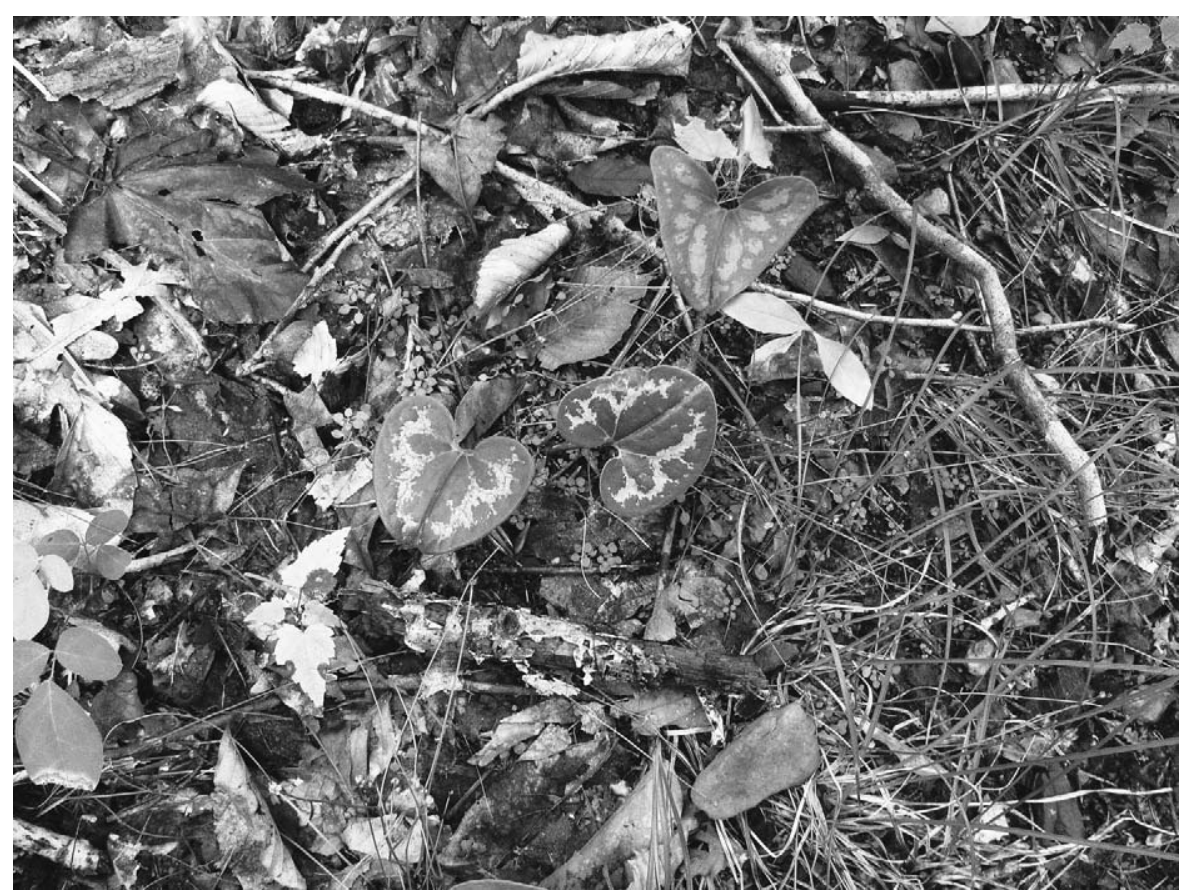

Plate 1. An example of the herbaceous understory community that is typically observed at the Oosting Nature Preserve, Duke Forest, North Carolina, USA. The charismatic and relatively uncommon Hexastylis sp. (Heartleaf) is in the center of the photo. Also pictured are two seedlings of the ubiquitous Acer rubrum (red maple). Photo credit: D. J. McGlinn.

2009). Species are typically treated as independently and randomly distributed in space or time. Of the two approaches, permutation procedures have the advantage that they may be constructed without additional assumptions of constant individual density in space or time, if each individual in the sampling units is enumerated (something that is difficult to obtain for many taxa). Several recent analytical treatments have demonstrated that explicitly incorporating the degree of intraspecific aggregation yields precise and accurate expected SRRs (Plotkin et al. 2000, Morlon et al. 2008, Shen et al. 2009). Importantly, these studies suggest that SRRs may be insensitive to patterns of interspecific association and are primarily signatures of intraspecific aggregation (Martin and Goldenfeld 2006). However, it is less clear how to interpret a model that fits an observed SRR that accounts for intraspecific aggregation but that may reflect the signature of other ecological or evolutionary mechanisms. Such models probably should not be treated as simple null models.

The more-individuals effect forms the basis of many mathematical treatments of SRRs. Its effect on the shape of a SRR is based on the relative abundance distribution of the species in the total area or total time period that is sampled (McGlinn and Palmer 2009). The two most commonly invoked forms of species abundance distributions are Preston's (1962) canonical lognormal distribution and the log-series distribution of Fisher et al. (1943). As the number of individuals in a sample increases, the lognormal distribution predicts that a SRR will be asymptotic, whereas the log-series does not. The log-series distribution has proportionally many more rare species than does a lognormal distribution; thus the rate of rise of an SRR is predicted to be faster under a log-series distribution. Unfortunately it is difficult to empirically estimate the species abundance distribution of the species pool and we have no a priori reason to prefer one particular distribution. The lognormal is most frequently assumed, typically with reference to Preston (1962), although the evidence for its ubiquity is weak. In general it is assumed that the more-individuals effect is most important over small spatial and temporal extents, although even over large extents its influence never goes to zero completely (Preston 1960, Palmer and Van Der Maarel 1995, White 2004, Carey et al. 2007, Magurran 2007). The relationship between a particular species abundance distribution and a SRR has a simple scaling relationship only if the individuals are randomly distributed (Green and Plotkin 2007), an assumption that will be violated by the other mechanisms we will discuss.

\section{Environmental heterogeneity}

As sampling increases to include more area or more time, more environmental variation may be encountered. If species differ in their ecological niches, that larger area or time will include more species (Triantis et al. 2003). Thus, SRRs may be caused by spatial or temporal environmental heterogeneity. A variety of 
kinds of mechanisms can lead to these effects. The exact predictions depend on the identity of mechanisms that are operating, in particular, how the interactions of organisms with their environments change with scale.

If the grain of the environmental heterogeneity is small with respect to the organisms' mobility, multiple species may coexist in the same community by classical niche partitioning. For example, ungulate species might specialize on different types of intermingled vegetation patches, or different species of aerial insectivore might coexist by feeding at different times of day. If the grain of the spatial or temporal heterogeneity is large with respect to the area encountered or the life span of individual organisms, the result is multiple communities existing in different parts of the area or at different times, e.g., forest communities dominated by different species in uplands vs. lowlands. Within a single year, species might use different seasonally available resources and so may only be present (or only apparent) during part of the year. Over multiple years, storage effects (Chesson and Huntly 1988, 1997, Chesson 2000, Kelly and Bowler 2005) can permit species to specialize on different year types (for example, wet vs. dry years) or on conditions that differ among successional stages.

All of this discussion is couched in terms of the matching of species with particular ecological requirements to particular subsets of the environment. In general, species sorting operates at local to regional scales as functions of niche requirements, migration rates, and distances. Over longer periods of time, evolutionary processes of character displacement create those niche differences. Among-species divergence is driven by competition and operates at the local to regional scales within which species interact. Withinspecies divergence most often is driven by adaptation to different environments that can lead to speciation. These processes generally occur at regional to global scales where rates of gene flow are low enough to allow for differentiation, although sympatric or parapatric speciation are also possible. Low rates of gene flow also can lead to divergence through genetic drift. For temporal SRRs, speciation would be relevant for relationships over geological timescales.

These processes have different effects on $\alpha$-, $\beta$-, and $\gamma$ diversity as well as on the shape of the SRR depending on the grain, focus, and extent of the samples relative to the grain of the environmental heterogeneity. Niche partitioning and storage effects lead to an increase in $\alpha$ diversity (more species at the grain of the sample) without necessarily changing $\gamma$-diversity. However, storage effects mean that sampling for more years will make it much more likely that one will add new species, leading to area-time interactions. In contrast, increasing the extent and focus of the samples will increase $\gamma$ diversity without necessarily changing $\alpha$-diversity. Finally, character displacement over evolutionary time can lead to SRRs that depend on phylogenetic relationships, with more closely related species within a genus or family being overdispersed at local to regional scales (Emerson and Gillespie 2008). The extent to which such phylogenetic relationships affect the shape of the SRR is an open question.

If we wish to understand the relationship between environmental heterogeneity and SRRs, we need to be able to measure and model environmental heterogeneity in ways that meaningfully capture how a set of species responds to that heterogeneity. Two general patterns of environmental heterogeneity have been proposed. Continuous variation in the form of spatially structured environmental gradients provides the basis of continuum theory (e.g., Gauch and Whittaker 1972, McGill and Collins 2003). In contrast, patchy variation in which the environment is a series of nested habitat patches forms the basis of hierarchy theory (e.g., Kolasa 1989, Wu and Loucks 1995). Both continuous and patchy variation in the environment exhibit distance decay (although of differing patterns) and can be modeled using fractal geometry (Palmer 1988, 1992, 2005, Nekola and White 1999). Such patterns have been related to SRRs. The Environmental Texture Hypothesis (ETH) posits that the slope of a SRR should be positively related to the rate of change in the environment, and that commonly observed patterns of scale dependence in SRRs reflect scale-specific changes in the texture of the environment (Palmer 2007, McGlinn and Palmer 2011). It may be possible to use the difference in shape between spatially explicit and nonspatially explicit SRRs as a measure of environmental heterogeneity (Chiarucci et al. 2009), but only if this heterogeneity has a simple scale-dependent pattern for all species.

Heterogeneity has ecological meaning only in the context of the biology of the species under consideration. Consequently, if the purpose of a SRR is to deduce processes, it is necessary to clearly define the set of species under consideration so that they are equivalent enough to be affected by the same set of environmental factors. To deduce process from pattern, it may be that the SRR alone is insufficient. Additional information, such as direct measures of environmental characteristics, is likely to be needed. If the purpose of the SRR is to estimate inventory diversity, such limitations may not hold. However, for extrapolations beyond the extent of a sample, information on environmental heterogeneity and how it increases as a function of area are critical, especially for designing an efficient sampling scheme.

\section{Dispersal effects}

SRRs are affected by the movement and dispersal limits of individuals and species. For a particular spatial or temporal extent, if all individuals of all species are uniformly distributed, and if the sampling unit is larger than the mean distance between individuals, all units would include all species and 
the slope of a SRR would be zero. If the sampling unit is smaller, there will be a positive slope until the grain of the SRR becomes larger than the mean distance. For randomly distributed individuals, the slope will be positive and greater than in the uniform case. Finally, if the distribution of individuals and species is clustered due to low dispersal ability, such as when offspring are found near parents, or when conspecifics disperse together (e.g., as with bird flocks or fish schools), a SRR would have a greater slope than either the uniform or the random case. Dispersal can also allow species to be found in a wider range of environments than otherwise through source-sink dynamics (Pulliam 1988, McPeek and Holt 1992, Diffendorfer 1998, Sears and Chesson 2007, Soininen 2010). In general, processes that lead to within-species aggregation will result in SRRs with lower intercepts and greater slopes. Processes that lead to amongspecies aggregation or within-species overdispersion will result in higher intercepts and lower slopes (He and Legendre 2002).

Processes that influence SRRs by affecting species' spatial and temporal dispersal ability typically operate at relatively small scales of space (i.e., local to landscape) or time (i.e., within a generation to few generations). The neutral theory (Hubbell 2001) predicts within-species clumping at regional extents and long time periods due to limited dispersal of newly arising species. Because the neutral theory posits that all species are ecologically equivalent, it predicts that the shape of the SRR will be the same at all scales. Although Hubbell (2001) contends that neutral processes would result in SRRs that follow a power law, that has been shown to be false (Rosindell and Cornell 2007).

\section{Biotic interactions}

Similar to dispersal, biotic interactions can influence the degree of within- and among-species aggregation. If conspecifics or different species competitively exclude one another, overdispersed or uniform distributions of species can occur. Conversely, clustered distributions can occur if facultative interactions dominate within communities. Exploitive interactions may cause either clustering or overdispersion. Clustered distributions can occur when a predator is frequently found with its prey, or even as consequences of habitat patchiness. Conversely, if interactions are strong and a predator extirpates its prey from sites, uniform distributions may occur.

We distinguish the biotic interactions discussed here from the environmental filtering processes described earlier based on a subtle, but critical, distinction: environmental filtering occurs in response to a background of environmental conditions that may be dynamic or static. In contrast, biotic interactions can result in a very dynamic environment in which the actors and their effects on each other are ever changing. This dynamic potentially results in a very different SRR, especially a SRR that attempts to simultaneously describe patterns in space and time. An open question is whether a general model can include all of the species in a community as well as within- and among-species dynamic processes. In general, these biotic interactions operate at local to landscape spatial extents and withingeneration to several-generation temporal extents. However, they can also operate through coevolution at regional extents (Thompson 1994).

\section{Multiple species pools}

In discussing the previous four processes, we assumed that there was a single pool of species whose dispersal across a landscape is not hindered by geographic boundaries. If the sampling regime of a particular SRR is broad enough to encompass long timescales or large areas, the shape of the SRR may be affected to the extent that those samples include multiple species pools, even when those pools lack crisp boundaries. For spacebased SRRs, this is most likely to occur at regional to global scales when crossing biogeographic or continental boundaries of migration (Rosenzweig 1995, Allen and White 2003). In these instances, the multiple species pools are the result of separate evolutionary histories. Time-based SRRs could encompass multiple species pools over large timescales due to taxonomic radiations and extinctions (Rosenzweig 1998, McKinney and Frederick 1999, Hadly and Maurer 2001, Raia et al. 2011). To some extent, the distinction among multiple species pools and local-scale dispersal limits or niche differentiation is one of degree, rather than kind.

\section{Causes of independent SRRS}

All of the previously described mechanisms influence the forms of both aggregate and independent SRRs. For the latter, depending on the scale of the SRR, two additional processes that encompass several of those mechanisms come to the fore: the interplay between immigration and local extinction, and the interplay between speciation and extinction.

Immigration-local extinction balance arises from the combined effects of the entry of new species into each unit (e.g., island), the establishment of those species, and their eventual disappearance through population extirpation. To include this mechanism, we must assume that a local population will persist only above some minimum size, with smaller populations going extinct due to the combined effects of low growth rates (the Allee effect; Stephens et al. 1999) and demographic stochasticity. If an area holds more individuals, more populations can attain species-specific minimum viable sizes. Thus, species richness should increase with area because a larger area is likely to contain more populations above the necessary minimum population size. In addition, the arrival of those species involves effects of dispersal limitation, and the establishment of those species will involve effects of environmental heterogeneity and biotic interactions. This process 
operates at landscape to regional scales and over long time periods. As an explanation for SRRs, it was proposed by Preston (1962) and is invoked most often as the basis of the MacArthur and Wilson (1967) theory of island biogeography.

Speciation-extinction balance operates over yet larger scales of time and space. It assumes a positive relationship between the number of individuals and the rate of speciation (VanderMeulen et al. 2001). This mechanism most often deals with species richness patterns at large spatial extents and, thus, is a basis for the existence of multiple species pools. However, smaller extents that are isolated by a great spatial distance, such as oceanic islands, can also experience independent speciation processes (Triantis et al. 2008).

\section{SAmpling Design}

The multiple interacting drivers of SRRs make causal inference a challenging task. The optimal sampling scheme clearly depends on how various processes affect the shape of the SRR. Those processes are scale dependent and different processes may operate at different scales. In addition, scale is defined by the biology of the focal taxa, which may differ in their characteristics. Any sampling scheme would perceive those processes in different ways, depending on the grain, extent, and spatial distribution of the samples relative to the scales at which the processes operate. Any subsequent analyses also would have to account for the spatial or temporal nonindependence of the samples (Veech and Crist 2010).

The effect of sampling schemes can be examined with simulation-based approaches. One can examine the ways in which different sampling schemes respond to particular patterns and then impose those different sampling schemes on a single data set. For example, a Type III scheme (noncontiguous units) can be derived from a Type II sampling scheme (contiguous units) simply by taking the data from every other sampling unit. More complex subsampling can also be done.

A direct measure of the influence of the number of individuals requires measuring abundances (e.g., Srivastava and Lawton 1998, Stiles and Scheiner 2010). Although this seems obvious, many biodiversity surveys do not assess abundance. Indeed, enumerating all of the unique individuals can be a major obstacle. When this is not possible or practical, an attempt should be made to design the sampling scheme such that it only captures stationary variation in the density of individuals across the sampling units (i.e., the mean density of individuals does not vary systematically across the samples). If the assumption of constant individual density can be reasonably made, then sample-based (rather than individual-based) rarefaction methods can be used to estimate the more-individuals effect (Gotelli and Colwell 2001). The vagility of the individuals should also be taken into consideration. For example, Coleman et al. (1982) studied the breeding birds on small islands in a lake. It was reasonable to assume that bird distributions were influenced by how many other individuals were on an island on a given day. Because individuals moved about an island during a day and this movement was much greater than movement among islands, it was reasonable to use "island" as the sampling unit. For long-lived, sessile organisms such a perennial plants, the sampling unit should be smaller than the average dispersal distance of offspring.

Assessing the influence of environmental heterogeneity requires both measuring the environment and sampling in a fashion relevant to the taxa under consideration. A particular environmental factor has a grain over which it may reasonably be considered homogenous and a configuration of patches of different types. On the other hand, a SRR inherently spans grains in a fashion that is dependent on the size of the sampling unit. For example, a sampling unit of $10 \times 10 \mathrm{~m}$ would be unable to detect changes in the environment on a range of $1 \mathrm{~m}$. In general, the size of the sampling unit should be no bigger than, and preferably smaller than, the grain of the environment. Because the grain of the environment is defined by the biology of the focal taxa, the uniformity of the environmental grain depends on the ecological equivalence of those taxa. One difficulty is in knowing what that grain would be prior to sampling. A possible solution involves a two-stage sampling process: first measure environmental parameters and then use that information to determine the environmental grain so as to guide the biotic samples.

Examining the influence of dispersal limitation also depends on the biology of the focal taxa. The sampling unit should be smaller than the mean dispersal of the least vagile species. The extent of the samples also sets an upper limit. For example, if the samples extend over 10 ha, then one can only draw conclusions about dispersal limitation over 5 ha, half that distance. In general, interpretations of results must be cognizant of the limits of the sampling scheme. The more species-rich or functionally diverse the assemblage, the more diverse the dispersal patterns and, thus the more imprecise or inaccurate the resulting predictions.

Studying the influence of biotic interactions on SRRs is probably the most difficult task. Lawton (1999) eloquently describes the decades of effort that he devoted to understanding the causes of diversity in one community of butterflies. It may be that at the level of communities, SRRs will never be an adequate tool for determining causal processes.

The effects of multiple species pools may be much more amenable to study through SRR patterns. Such SRRs would encompass large geographic extents. For example, the expected sharp change in the rate of rise in SRRs could be used to identify whether a biogeographic barrier was crossed or if there was a change in the texture of the environment at those scales (Rosenzweig 1995, Fridley et al. 2005). 
SRRs frequently display scale dependence in which their rates of increase change with the grain and extent of the analysis (Scheiner 2003). For example, Stiles and Scheiner (2007) found that SRRs estimated within desert habitat islands were asymptotic, whereas the SRR estimated from multiple islands was nonasymptotic. For the data from the Oosting Natural Area, all but one of the best-fit SRRs were asymptotic (Table 2, Fig. 3). Changes in the curvature of a spatially explicit SRR at a particular grain suggests that a habitat or geographic boundary has been crossed, and thus new, and probably ecologically different, species are being sampled (Rosenzweig 1995). Similarly, changes in the curvature of a richness-time relationship indicate that some type of temporal boundary has been crossed, such as a change of seasons. Changes in the curvature of both spatial and temporal SRRs may reflect changes in the species abundance distribution of multiple species pools (McGlinn and Palmer 2009).

\section{Models And AnAlyses}

The preceding discussion should not imply that little progress can be made in understanding the genesis of empirical SRRs. Although multiple causes operating at multiple scales present formidable difficulties, one way to make progress is with modeling. By building models that independently manipulate processes and sampling schemes, it may be possible to find cases in which different processes and sampling schemes produce distinguishing patterns that can provide causal inference for empirical patterns.

For example, recent theoretical work by Harte et al. (2009) argues that all SRRs lie along the same curve. Their analysis, however, leads to the conclusion that this curve behaves like a power law only when the number of individuals per species becomes very large and the slope of the SRR approaches zero. Empirical SRRs, as shown by Harte et al. (2009), vary considerably in shape. Other recent work has developed new modeling frameworks that combine sampling effects with processes that result in interspecific aggregation (Plotkin et al. 2000, Morlon et al. 2008, Shen et al. 2009). Such models can be used to identify processes and scales that produce distinguishable patterns, thus providing effective guidelines for future research. Conversely, we may discover that some processes cannot be distinguished using SRRs.

The way in which the data are aggregated into an SRR can also be varied. Type A and B SRRs differ in whether they retain the spatial or temporal arrangement of the sampling units during aggregation. If dispersal limitation influences the shape of the SRR, then Type A and B curves constructed from the same data would show different patterns. Similarly, those two types of SRRs would differ if the pattern of environmental heterogeneity is continuous vs. patchy in space or consists of continuous changes vs. a temporal succession of discrete conditions in time.
A particular analysis has a grain, focus, and extent in space and time as well as a specified set of species that may be defined taxonomically (e.g., vascular plants, bats) or functionally (e.g., herbivores). As discussed earlier, the biology of the focal taxa determines the effects of the various mechanisms. If so, a SRR constructed using a mix of taxa from different clades or with different ecologies may have a very different shape than one constructed from more similar species. It may be more difficult to discern process from pattern in such a situation, suggesting that a given SRR should be confined to species with similar life-forms or functional traits. On the other hand, if one can construct hypotheses about differences in the importance of various processes based on differences in species' biology, differences in SRRs may provide a test of those hypotheses. Of course, if the purpose of the SRR is to describe biodiversity rather than to infer process, then a mix of taxa may be highly appropriate.

\section{Conclusions}

It is important to separate the use of SRRs to estimate diversity from their use to understand the causes of diversity patterns. The former use goes to the origins of SRRs and is relatively straightforward. Understanding that different types of SRRs estimate different components of diversity ( $\alpha$ - vs. $\gamma-$, and not $\beta$-) is an important advance. For these purposes, arguments over the spatial or temporal contiguity of samples and the mathematical form of the function should be relegated to the realm of sampling theory and statistics, rather than treating them as ecological issues. The latter use, understanding causes, is much more difficult. We currently understand little about how all of the possible processes might influence the form of SRRs. The field is ripe for the study of these effects through simulation modeling. We will need to build more complex models if we are to have any hope of deducing process from pattern.

A key message of this paper is that we should not be hung up on words. Much of the recent debate about SRRs is whether the title "species-area curve" should be reserved for only some types of relationships, as if that graces those types with some special properties (e.g., Gray et al. 2004a, Dengler 2009). Instead, we need to understand the entire variety of SRRs and their relationships to each other. Different types serve different functions and provide different kinds of information.

We also need to take a step back from assumed common knowledge about the functional form of SRRs. In ecology, it is almost always a mistake to assume a single cause for any ecological pattern. Similarly, it is almost always a mistake to claim that a single pattern holds everywhere, as has been done with the assumption that SRRs are always power functions. The failure to examine other functions means that we may be missing much of the variation in pattern. It may be that such variation holds valuable information about the process- 
es that determine how individuals and species are distributed. We won't know until we look.

\section{ACKNOWLEDGMENTS}

We thank Thomas Crist and an anonymous reviewer for their useful criticisms of an earlier version. This manuscript is based on work done by S. M. Scheiner while serving at the National Science Foundation (NSF). The views expressed in this paper do not necessarily reflect those of the National Science Foundation or the United States Government. Support to G. A. Fox was provided in part by NSF grant DEB0614468. M. R. Helmus was funded by a NSF Bioinformatics fellowship (DBI-0906011). D. J. McGlinn thanks A. Hurlburt for postdoctoral funding. Support to M. R. Willig was provided in part by NSF grant DEB-0614468. Order of coauthorship is alphabetical.

\section{Literature Cited}

Adler, P. B. 2004. Neutral models fail to reproduce observed species-time and species-area relationships in Kansas grasslands. Ecology 85:1265-1272.

Adler, P. B., and W. K. Lauenroth. 2003. The power of time: spatiotemporal scaling of species diversity. Ecology Letters 6:749-756.

Adler, P. B., E. P. White, W. K. Lauenroth, D. M. Kaufman, A. Rassweiler, and J. A. Rusak. 2005. Evidence for a general species-time-area relationship. Ecology 86:2032-2039.

Allen, A. P., and E. P. White. 2003. Effects of range size on species-area relationships. Evolutionary Ecology Research 5:493-499.

Anjos, M. B. Dos, J. Zuanon. 2007. Sampling effort and fish species richness in small terra firme forest streams of central Amazonia, Brazil. Neotropical Ichthyology 5:45-52.

Arnolds, E. J. M. 1981. Ecology and coenology of macrofungi in grasslands and moist heathlands in Drenthe, The Netherlands. Part 1. Introduction and synecology. Bibliotheca Mycologica 83:1-410.

Arrhenius, O. 1921. Species and area. Journal of Ecology 9:9599.

Barkman, J. J. 1989. A critical evaluation of minimum area concepts. Plant Ecology 85:89-104.

Baselga, A. 2010. Multiplicative partition of true diversity yields independent alpha and beta components; additive partition does not. Ecology 91:1974-1981.

Bierregaard, R. O., Jr., C. Gascon, T. E. Lovejoy, and R. Mesquita. 2001. Lessons from Amazonia: the ecology and conservation of a fragmented forest. Yale University Press, New Haven, Connecticut, USA.

Braun-Blanquet, J. 1932. Plant sociology: the study of plant communities. McGraw-Hill, New York, New York, USA.

Cain, S. A. 1938. The species-area curve. American Midland Naturalist 19:573-581.

Cannon, C. H., D. R. Peart, and M. Leighton. 1998. Tree species diversity in commercially logged Bornean rainforest. Science 281:1366-1368.

Carey, S., A. Ostling, J. Harte, and R. d. Moral. 2007. Impact of curve construction and community dynamics on the species-time relationship. Ecology 88:2145-2153.

Chesson, P. 2000. Mechanisms of maintenance of species diversity. Annual Review of Ecology and Systematics 31:343-366.

Chesson, P., and N. Huntly. 1997. The roles of harsh and fluctuating conditions in the dynamics of ecological communities. American Naturalist 150:519-553.

Chesson, P. L., and N. Huntly. 1988. Community consequences of life history traits in a variable environment. Annales Zoologici Fennici 25:5-16.

Chiarucci, A. 1996. Species diversity in plant communities on ultramafic soils in relation to pine afforestation. Journal of Vegetation Science 7:57-62.
Chiarucci, A., G. Bacaro, D. Rocchini, and L. Fattorini. 2008. Discovering and rediscovering the sample-based rarefaction formula in the ecological literature. Community Ecology 9:121-123.

Chiarucci, A., G. Bacaro, D. Rocchini, C. Ricotta, M. W. Palmer, and S. M. Scheiner. 2009. Spatially constrained rarefaction: incorporating the autocorrelated structure of biological communities in sample-based rarefaction. Community Ecology 10:209-214.

Chiarucci, A., S. Maccherini, and V. De Dominicis. 2001. Evaluation and monitoring of the flora in a nature reserve by estimation methods. Biological Conservation 101:305-314.

Chytrý, M., and Z. Otýpková. 2003. Plot sizes used for phytosociological sampling of European vegetation. Journal of Vegetation Science 14:563-570.

Coleman, B. D. 1981. On random placement and species-area relations. Mathematical Biosciences 54:191-215.

Coleman, B. D., M. A. Mares, M. R. Willig, and Y.-H. Hsieh. 1982. Randomness, area, and species richness. Ecology 63:1121-1133.

Collins, M., and D. Simberloff. 2009. Rarefaction and nonrandom spatial dispersion patterns. Environmental and Ecological Statistics 16:89-103.

Colwell, R. K., and J. A. Coddington. 1994. Estimating terrestrial biodiversity through extrapolation. Philosophical Transactions of the Royal Society of London B 345:101-118.

Colwell, R. K., C. X. Mao, and J. Chang. 2004. Interpolating, extrapolating, and comparing incidence-based species accumulation curves. Ecology 85:2717-2727.

Condit, R., S. P. Hubbell, J. V. LaFrankie, R. Sukumar, N. Manokaran, R. B. Foster, and P. S. Ashton. 1996. Speciesarea and species-individual relationships for tropical trees: a comparison of three 50-ha plots. Journal of Ecology 84:549562

Connor, E. F., and E. D. McCoy. 1979. The statistics and biology of the species-area relationship. American Naturalist 113:791-833.

Crist, T. O., and J. A. Veech. 2006. Additive partitioning of rarefaction curves and species-area relationships: unifying $\alpha-$, $\beta$ - and $\gamma$-diversity with sample size and habitat area. Ecology Letters 9:923-932.

de Candolle, A. 1855. Géographie botanique raisonnée: ou l'exposition des faits principaux et des lois concernant la distribution géographique des plates de l'epoque actuelle. Maisson, Paris, France.

De Dominicis, V., and C. Barluzzi. 1983. Coenological research on macrofungi in evergreen oak woods in the hills near Siena (Italy). Plant Ecology 54:177-187.

Dengler, J. 2008. Pitfalls in small-scale species-area sampling and analysis. Folia Geobotanica 43:269-287.

Dengler, J. 2009. Which function describes the species-area relationship best? A review and empirical evaluation. Journal of Biogeography 36:728-744.

Dengler, J., and J. Oldeland. 2010. Effects of sampling protocol on the shapes of species richness curves. Journal of Biogeography 37:1698-1705.

Desmet, P., and R. Cowling. 2004. Using the species-area relationship to set baseline targets for conservation. Ecology and Society 9(12):11. 〈http://www.ecologyandsociety.org/ vol19/iss 12/art11/)

Diffendorfer, J. E. 1998. Testing models of source-sink dynamics and balanced dispersal. Oikos 81:417-433.

Drakare, S., J. J. Lennon, and H. Hillebrand. 2006. The imprint of the geographical, evolutionary and ecological context on species-area relationships. Ecology Letters 9:215-227.

Dungan, J. L., J. N. Perry, M. R. T. Dale, P. Legendre, S. Citron-Pousty, M. J. Fortin, A. Jakomulska, M. Miriti, and M. S. Rosenberg. 2002. A balanced view of scale in spatial statistical analysis. Ecography 25:626-640.

Emerson, B. C., and R. G. Gillespie. 2008. Phylogenetic analysis of community assembly and structure over space and time. Trends in Ecology and Evolution 23:619-630. 
Engen, S. 1976. A note on the estimation of the species-area curve. ICES Journal of Marine Science 36:286-288.

Fisher, R. A., A. S. Corbet, and C. B. Williams. 1943. The relation between the number of species and the number of individuals in a random sample of an animal population. Journal of Animal Ecology 12:42-58.

Fridley, J. D., R. K. Peet, E. van der Maarel, and J. H. Willems. 2006. Integration of local and regional species-area relationships from space-time species accumulation. American Naturalist 168:133-143.

Fridley, J. D., R. K. Peet, T. R. Wentworth, and P. S. White. 2005. Connecting fine- and broad-scale species-area relationships of southeastern U.S. flora. Ecology 86:1173-1177.

Gauch, H. G., Jr., and R. H. Whittaker. 1972. Coenocline simulation. Ecology 53:446-451.

Gitay, H., S. H. Roxburgh, and J. B. Wilson. 1991. Speciesarea relations in a New Zealand tussock grassland, with implications for nature reserve design and for community structure. Journal of Vegetation Science 2:113-118.

Gleason, H. A. 1922. On the relation between species and area. Ecology 3:158-162.

Gotelli, N. J., and R. K. Colwell. 2001. Quantifying biodiversity: procedures and pitfalls in the measurement and comparison of species richness. Ecology Letters 4:379-391.

Gray, J. S., K. I. Ugland, and J. Lambshead. 2004a. On species accumulation and species-area curves. Global Ecology and Biogeography 13:567-568.

Gray, J. S., K. I. Ugland, and J. Lambshead. 2004b. Species accumulation and species area curves: a comment on Scheiner (2003). Global Ecology and Biogeography 13:473476.

Green, J. L., and J. B. Plotkin. 2007. A statistical theory for sampling species abundances. Ecology Letters 10:1037-1045.

Grinnell, J. 1922. The role of the "accidental." Auk 39:373-380.

Guilhaumon, F., O. Gimenez, K. J. Gaston, and D. Mouillot. 2008. Taxonomic and regional uncertainty in species-area relationships and the identification of richness hotspots. Proceedings of the National Academy of Sciences USA 105:15458-15463.

Guilhaumon, F., D. Mouillot, and O. Gimenez. 2010. mmSAR: an R-package for multimodel species-area relationship inference. Ecography 33:420-424.

Gurevitch, J., S. M. Scheiner, and G. A. Fox. 2006. The ecology of plants. Second edition. Sinauer Associates, Sunderland, Massachusetts, USA.

Hadly, E. A., and B. A. Maurer. 2001. Spatial and temporal patterns of species diversity in montane mammal communities of western North America. Evolutionary Ecological Research 3:477-486.

Harcourt, A. H., S. A. Parks, and R. Woodroffe. 2001. Human density as an influence on species/area relationships: double jeopardy for small African reserves? Biodiversity and Conservation 10:1011-1026.

Harte, J., A. Kinzig, and J. Green. 1999a. Self-similarity in the distribution and abundance of species. Science 284:334-336.

Harte, J., S. McCarthy, K. Taylor, A. Kinzig, and M. L. Fisher. 1999b. Estimating species-area relationships from plot to landscape scale using spatial-turnover data. Oikos 86:45-54.

Harte, J., A. B. Smith, and D. Storch. 2009. Biodiversity scales from plots to biomes with a universal species-area curve. Ecology Letters 12:789-797.

He, F., and P. Legendre. 1996. On species-area relations. American Naturalist 148:719-737.

He, F., and P. Legendre. 2002. Species diversity patterns derived from species-area models. Ecology 83:1185-1198.

Helmus, M. R., T. J. Bland, C. K. Williams, and A. R. Ives. 2007. Phylogenetic measures of biodiversity. American Naturalist 169:E68-E83.

Hill, J. L., and P. J. Curran. 2001. Species composition in fragmented forests: conservation implications of changing forest area. Applied Geography 21:157-174.
Hill, J. L., P. J. Curran, and G. M. Foody. 1994. The effect of sampling on the species-area curve. Global Ecology and Biogeography 4:97-106.

Hill, M. O. 1973. Diversity and evenness: a unifying notation and its consequences. Ecology 54:427-432.

Holthe, T. 1975. A method for the calculation of ordinate values of the cumulative species-area curve. ICES Journal of Marine Science 36:183-184.

Hubbell, S. P. 2001. The unified neutral theory of biodiversity and biogeography. Princeton University Press, Princeton, New Jersey, USA.

Hubbell, S. P., F. He, R. Condit, L. Borda-de-Água, J. Kellner, and $\mathrm{H}$. ter Steege. 2008. How many tree species are there in the Amazon and how many of them will go extinct? Proceedings of the National Academy of Sciences USA 105:11498-11504.

Inouye, R. S. 1998. Species-area curves and estimates of total species richness in an old-field chronosequence. Plant Ecology 137:31-40.

Jaccard, P. 1901. Distribution de la flore alpine dans le Bassin des Dranes et dans quelques régions voisines. Bulletin Société Vaudoise des Sciences Naturelles 37:241-272.

Jaccard, P. 1908. Nouvelles recherches sur la distribution florale. Bulletin de la Societe Vaudoise des Sciences Naturelles 44:223-270.

Jost, L. 2006. Entropy and diversity. Oikos 113:363-375.

Jost, L. 2007. Partitioning diversity into independent alpha and beta components. Ecology 88:2427-2439.

Jurasinski, G., V. Retzer, and C. Beierkuhnlein. 2009. Inventory, differentiation, and proportional diversity: a consistent terminology for quantifying species diversity. Oecologia 159:15-26.

Keeley, J. E. 2003. Relating species abundance distributions to species-area curves in two Mediterranean-type shrublands. Diversity and Distributions 9:253-259.

Keeley, J. E., and C. J. Fotheringham. 2003. Species-area relationships in Mediterranean-climate plant communities. Journal of Biogeography 30:1629-1657.

Kelly, C. K., and M. G. Bowler. 2005. A new application of storage dynamics: differential sensitivity, diffuse competition, and temporal niches. Ecology 86:1012-1022.

Kobayashi, S. 1974. The species-area relation I. A model for discrete sampling. Researches in Population Ecology 15:223237.

Kolasa, J. 1989. Ecological systems in hierarchical perspective: breaks in community structure and other consequences. Ecology 70:36-47.

Lawton, J. H. 1999. Are there general laws in ecology? Oikos 84:177-192.

Lawton, J. H. 2000. Community ecology in a changing world. Inter-Research Science Center and International Ecology Institute, Oldendorf/Luhe, Germany.

Lindenmayer, D. B. 2008. Large scale landscape experiments: lessons from Tumut. Cambridge University Press, Cambridge, UK.

Lomolino, M. V. 2000. Ecology's most general, yet protean pattern: the species-area relationship. Journal of Biogeography $27: 17-26$.

Lyons, M. M., J. E. Ward, H. Gaff, R. E. Hicks, J. M. Drake, and F. C. Dobbs. 2010. Theory of island biogeography on a microscopic scale: organic aggregates as islands for aquatic pathogens. Aquatic Microbial Ecology 60:1-13.

Lyons, S. K., and M. R. Willig. 1999. A hemispheric assessment of scale dependence in latitudinal gradients of species richness. Ecology 80:2483-2491.

Lyons, S. K., and M. R. Willig. 2002. Species richness, latitude, and scale-sensitivity. Ecology 83:47-58.

MacArthur, R. H., and E. O. Wilson. 1967. The theory of island biogeography. Princeton University Press, Princeton, New Jersey, USA.

Magurran, A. E. 2007. Species abundance distributions over time. Ecology Letters 10:347-354. 
Martin, H. G., and N. Goldenfeld. 2006. On the origin and robustness of power-law species-area relationships in ecology. Proceedings of the National Academy of Sciences USA 103:10310-10315.

May, R. M. 1975. Patterns of species abundance and diversity. Pages 81-120 in M. L. Cody and J. L. Diamond, editors. Ecology and evolution of communities. Harvard University Press, Cambridge, Massachusetts, USA.

McGill, B. J. 2003. Does Mother Nature really prefer rare species or are log-left-skewed SADs a sampling artefact? Ecology Letters 6:766-773.

McGill, B., and C. Collins. 2003. A unified theory for macroecology based on spatial patterns of abundance. Evolutionary Ecology Research 5:469-492.

McGlinn, D. J., and M. W. Palmer. 2009. Modeling the sampling effect in the species-time-area relationship. Ecology 90:836-846.

McGlinn, D. J., and M. W. Palmer. 2011. Quantifying the influence of environmental texture on the rate of species turnover: evidence from two habitats. Plant Ecology, in press.

McGuinness, K. A. 1984. Equations and explanations in the study of species-area curves. Biological Reviews 59:423-440.

McKinney, M. L., and D. L. Frederick. 1999. Species-time curves and population extremes: ecological patterns in the fossil record. Evolutionary Ecology Research 1:641-650.

McPeek, M. A., and R. D. Holt. 1992. The evolution of dispersal in spatially and temporally varying environments. American Naturalist 140:1010-1027.

Morlon, H., G. Chuyong, R. Condit, S. Hubbell, D. Kenfack, D. Thomas, R. Valencia, and J. L. Green. 2008. A general framework for the distance-decay of similarity in ecological communities. Ecology Letters 11:904-917.

Nekola, J. C., and P. S. White. 1999. The distance decay of similarity in biogeography and ecology. Journal of Biogeography 26:867-878.

Paivinen, J., P. Ahlroth, V. Kaitala, and J. Suhonen. 2004. Species richness, abundance and distribution of myrmecophilous beetles in nests of Formica aquilonia ants. Annales Zoologici Fennici 41:447-454.

Palmer, M. W. 1988. Fractal geometry: a tool for describing spatial patterns of plant communities. Plant Ecology 75:91102.

Palmer, M. W. 1992. The coexistence of species in fractal landscapes. American Naturalist 139:375-397.

Palmer, M. W. 2005. Distance decay in an old-growth neotropical forest. Journal of Vegetation Science 16:161-166.

Palmer, M. W. 2007. Species-area curves and the geometry of nature. Pages 15-31 in D. Storch, P. L. Marquet, and J. H. Brown, editors. Scaling biodiversity. Cambridge University Press, Cambridge, UK.

Palmer, M. W., D. J. McGlinn, and J. D. Fridley. 2008. Artifacts and artifictions in biodiversity research. Folia Geobotanica 43:245-257.

Palmer, M. W., R. K. Peet, R. A. Reed, W. Xi, and P. S. White. 2007. A multiscale study of vascular plants in a North Carolina piedmont forest. Ecology 88:2674.

Palmer, M. W., and E. Van Der Maarel. 1995. Variance in species richness, species associations, and niche limitations. Oikos 73:203-213.

Palmer, M. W., and P. S. White. 1994. Scale dependence and the species-area relationship. American Naturalist 144:717740.

Passy, S. I., and F. G. Blanchet. 2007. Algal communities in human-impacted stream ecosystems suffer beta-diversity decline. Diversity and Distributions 13:670-679.

Peet, R. K., T. R. Wentworth, and P. S. White. 1998. A flexible, multipurpose method for recording vegetation composition and structure. Castanea 63:262-274.

Petchey, O. L., and K. J. Gaston. 2002. Functional diversity (FD), species richness and community composition. Ecology Letters 5:402-411.
Plotkin, J. B., M. D. Potts, N. Leslie, N. Manokaran, J. V. LaFrankie, and P. S. Ashton. 2000. Species-area curves, spatial aggregation, and habitat specialization in tropical forests. Journal of Theoretical Biology 207:81-99.

Preston, F. W. 1960. Time and space and the variation of species. Ecology 41:612-627.

Preston, F. W. 1962. The canonical distribution of commonness and rarity: part I. Ecology 43:185-215.

Pulliam, H. R. 1988. Sources, sinks, and population regulation. American Naturalist 132:652-661.

Raia, P., F. Carotenuto, C. Meloro, P. Piras, and C. Barbera. 2011. Species accumulation over space and time in European Plio-Holocene mammals. Evolutionary Ecology 25:171-188.

Reed, R. A., R. K. Peet, M. W. Palmer, and P. S. White. 1993. Scale dependence of vegetation-environment correlations: a case study of a North Carolina piedmont woodland. Journal of Vegetation Science 4:329-340.

Rejmánek, M., and E. Rosén. 1992. Cycles of heterogeneity during succession: a premature generalization? Ecology 73:2329-2331.

Ricotta, C., M. L. Carranza, and G. Avena. 2002. Computing $\beta$-diversity from species-area curves. Basic and Applied Ecology 3:15-18.

Rosenzweig, M. L. 1995. Species diversity in space and time. Cambridge University Press, Cambridge, UK.

Rosenzweig, M. L. 1998. Preston's ergodic conjecture: the accumulation of species in space and time. Pages $311-348$ in M. L. McKinney, editor. Biodiversity dynamics: turnover of populations, taxa, and communities. Columbia University Press, New York, New York, USA.

Rosindell, J., and S. J. Cornell. 2007. Species-area relationships from a spatially explicit neutral model in an infinite landscape. Ecology Letters 10:586-595.

Sagar, R., A. S. Raghubanshi, and J. S. Singh. 2003. Asymptotic models of species-area curve for measuring diversity of dry tropical forest tree species. Current Science 84:1555-1560.

Sanders, H. L. 1968. Marine benthic diversity: a comparative study. American Naturalist 102:243-282.

Scheiner, S. M. 1992. Measuring pattern diversity. Ecology 73:1860-1867.

Scheiner, S. M. 2003. Six types of species-area curves. Global Ecology and Biogeography 12:441-447.

Scheiner, S. M. 2004. A mélange of curves: further dialogue about species-area relationships. Global Ecology and Biogeography 13:479-484.

Scheiner, S. M. 2009. The terminology and use of species-area relationships: reply to Dengler. Journal of Biogeography 36:2005-2012.

Scheiner, S. M., S. B. Cox, M. R. Willig, G. G. Mittelbach, C. Osenberg, and M. Kaspari. 2000. Species richness, speciesarea curves, and Simpson's paradox. Evolutionary Ecology Research 2:791-802.

Schmit, J. P. 2005. Species richness of tropical wood-inhabiting macrofungi provides support for species-energy theory. Mycologia 97:751-761.

Schoener, T. W. 1976. The species-area relation with archipelagos: models and evidence from island land birds. Pages 629642 in H. J. Frith and J. H. Calaby, editors. Proceedings of the 16th International Ornithological Conference. Australian Academy of Science, Canberra, Australian Capital Territories, Australia.

Sears, A. L. W., and P. Chesson. 2007. New methods for quantifying the spatial storage effect: an illustration with desert annuals. Ecology 88:2240-2247.

Shen, G., M. Yu, X.-S. Hu, X. Mi, H. Ren, I. F. Sun, and K. Ma. 2009. Species-area relationships explained by the joint effects of dispersal limitation and habitat heterogeneity. Ecology 90:3033-3041.

Shen, T.-J., and F. He. 2008. An incidence-based richness estimator for quadrats sampled without replacement. Ecology 89:2052-2060. 
Shinozaki, K. 1963. Note on the species area curve. Pages 1-5 in Proceedings of the 10th Annual Meeting of the Ecological Society of Japan. Ecological Society of Japan, Tokyo, Japan.

Shmida, A. 1984. Whittaker's plant diversity sampling method. Israel Journal of Botany 33:41-46.

Shurin, J. B. 2007. How is diversity related to species turnover through time? Oikos 116:957-965.

Shurin, J. B., S. E. Arnott, H. Hillebrand, A. Longmuir, B. Pinel-Alloul, M. Winder, and N. D. Yan. 2007. Diversitystability relationship varies with latitude in zooplankton. Ecology Letters 10:127-134.

Smith, E. P., P. M. Stewart, and J. Cairns. 1985. Similarities between rarefaction methods. Hydrobiologia 120:167-170.

Soberón, M. J., and B. J. Llorente. 1993. The use of species accumulation functions for the prediction of species richness. Conservation Biology 7:480-488.

Soininen, J. 2010. Species turnover along abiotic and biotic gradients: patterns in space equal patterns in time? BioScience 60:433-439.

Srivastava, D. S., and J. H. Lawton. 1998. Why more productive sites have more species: an experimental test of theory using tree-hole communities. American Naturalist 152:510-529.

Stephens, P. A., W. J. Sutherland, and R. P. Freckleton. 1999. What is the Allee effect? Oikos 87:185-190.

Stiles, A., and S. M. Scheiner. 2007. Evaluation of species-area functions using Sonoran Desert plant data: not all speciesarea curves are power functions. Oikos 116:1930-1940.

Stiles, A., and S. M. Scheiner. 2010. A multi-scale analysis of fragmentation effects on remnant plant species richness in Phoenix, Arizona. Journal of Biogeography 37:1721-1729.

Stohlgren, T. J., M. B. Falkner, and L. D. Schell. 1995. A modified-Whittaker nested vegetation sampling method. Plant Ecology 117:113-121.

Sugihara, G. 1981. $S=C A^{z}, z \approx 1 / 4$ : a reply to Conner and McCoy. American Naturalist 117:790-793.

Thompson, J. N. 1994. The coevolutionary process. University of Chicago Press, Chicago, Illinois, USA.

Tjørve, E. 2003. Shapes and functions of species-area curves: a review of possible models. Journal of Biogeography 30:827835.

Tjørve, E. 2009. Shapes and functions of species-area curves (II): a review of new models and parameterizations. Journal of Biogeography 36:1435-1445.

Triantis, K. A., M. Mylonas, K. Lika, and K. Vardinoyannis. 2003. A model for the species-area-habitat relationship. Journal of Biogeography 30:19-27.

Triantis, K. A., M. Mylonas, and R. J. Whittaker. 2008. Evolutionary species-area curves as revealed by single-island endemics: insights for the inter-provincial species-area relationship. Ecography 31:401-407.
Tuomisto, H. 2010a. A diversity of beta diversities: straightening up a concept gone awry. Part 1. Defining beta diversity as a function of alpha and gamma diversity. Ecography 33:222.

Tuomisto, H. 2010b. A diversity of beta diversities: straightening up a concept gone awry. Part 2. Quantifying beta diversity and related phenomena. Ecography 33:23-45.

Turner, W. R., and E. Tjørve. 2005. Scale-dependence in species-area relationships. Ecography 28:721-730.

Ulrich, W., and J. Buszko. 2003. Species-area relationships of butterflies in Europe and species richness forecasting. Ecography 26:365-373.

van der Maarel, E. 1996. Vegetation dynamics and dynamic vegetation science. Acta Botanica Neerlandica 45:421-442.

VanderMeulen, M. A., A. J. Hudson, and S. M. Scheiner. 2001. Three evolutionary hypotheses for the hump-shaped productivity-diversity curve. Evolutionary Ecology Research 3:379392.

Veech, J. A., and T. O. Crist. 2010. Diversity partitioning without statistical independence of alpha and beta. Ecology 91:1964-1969.

Wardle, D. A., O. Zackrisson, G. Hörnberg, and C. Gallet. 1997. The influence of island area on ecosystem properties. Science 277:1296-1299.

White, E. P. 2004. Two-phase species-time relationships in North American land birds. Ecology Letters 7:329-336.

White, E. P., P. B. Adler, W. K. Lauenroth, R. A. Gill, D. Greenberg, D. M. Kaufman, A. Rassweiler, J. A. Rusak, M. D. Smith, J. R. Steinbeck, R. B. Waide, and J. Yao. 2006. A comparison of the species-time relationship across ecosystems and taxonomic groups. Oikos 112:185-195.

Whittaker, R. H. 1960. Vegetation of the Siskiyou Mountains, Oregon and California. Ecological Monographs 30:279-338.

Whittaker, R. H. 1972. Evolution and measurement of species diversity. Taxon 21:213-251.

Whittaker, R. J., K. J. Willis, and R. Field. 2001. Scale and species richness: towards a general, hierarchical theory of species diversity. Journal of Biogeography 28:453-470.

Williams, M. R. 1995. An extreme-value function model of the species incidence and species-area relations. Ecology 76:2607-2616.

Wilson, J. B., and A. Chiarucci. 2000. Do plant communities exist? Evidence from scaling-up local species-area relations to the regional level. Journal of Vegetation Science 11:773775 .

Wissel, C., and B. Maier. 1992. A stochastic model for the species-area relationship. Journal of Biogeography 19:355362.

Wu, J., and O. L. Loucks. 1995. From balance of nature to hierarchical patch dynamics: a paradigm shift in ecology. Quarterly Review of Biology 70:439-466. 